\title{
Two new species of Leptanilloides Mann, 1823 (Formicidae: Dorylinae) from the Andes of southern Ecuador
}

\author{
Thibaut DELSINNE ${ }^{1,4, *}$, Gontran SONET $^{2}$ \& David A. DONOSO ${ }^{1,3}$ \\ ${ }^{1}$ Universidad Técnica Particular de Loja (UTPL), Departamento de Ciencias Naturales, \\ Museo de Colecciones Biológicas (MUTPL), Loja, Ecuador. \\ ${ }^{2}$ Royal Belgian Institute of Natural Sciences, Joint Experimental Molecular Unit (JEMU) \\ - OD Taxonomy and Phylogeny, Vautierstraat 29, B-1000 Brussels, Belgium. \\ ${ }^{3}$ Universidad de Cuenca, Facultad de Ciencias, Agropecuarias, Ave. 12 de Abril s/n, Cuenca, Ecuador \\ ${ }^{*}$ Corresponding author: delsinnethibaut $@$,yahoo.fr \\ ${ }^{2}$ E-mail: gontran.sonet@naturalsciences.be \\ ${ }^{3}$ E-mail: david.donosov@gmail.com \\ ${ }^{4}$ urn:1sid:zoobank.org:author:BA819CA7-A1BC-43AC-94A3-9DBB2D89D634 \\ ${ }^{2}$ urn:Isid:zoobank.org:author:BA7353F8-5296-4968-9D2D-D474EF8FCEB6 \\ ${ }^{3}$ urn:Isid:zoobank.org:author:BD09BA33-A9F8-4F77-A5B3-F277062FB286
}

\begin{abstract}
Two new species of Leptanilloides are described: L. copalinga Delsinne \& Donoso sp. nov. and L. prometea Delsinne \& Donoso sp. nov., based on workers collected in the leaf litter and soil of the Andes of southern Ecuador. Both species belong to the L. biconstricta species-group (formally diagnosed here). The metatibial gland, considered a synapomorphy for Dorylinae, is observed in L. prometea sp. nov. but seems absent in L. copalinga sp. nov. We provide a COI DNA barcode for both species and a revised key for the worker caste of all known species in the genus. We also describe a single male identified as a potential new Leptanilloides species on the basis of morphology. Furthermore, its mitochondrial COI gene sequence does not match any previously barcoded species. However, we refrain from giving it a specific name because of our lack of knowledge about the worker caste. So far, half of the 14 Leptanilloides species have been discovered above $1500 \mathrm{~m}$ in the mountain forests or páramos of the Ecuadorian Andes, confirming, if needed, the biological significance of these threatened habitats.
\end{abstract}

Key words. Army ant syndrome, DNA barcoding, male description, metatibial gland, subterranean ants.

Delsinne T., Sonet G. \& Donoso D.A. 2015. Two new species of Leptanilloides Mann, 1823 (Formicidae: Dorylinae) from the Andes of southern Ecuador. European Journal of Taxonomy 143: 1-35. http://dx.doi. org/10.5852/ejt.2015.143

\section{Introduction}

The ant genus Leptanilloides Mann, 1923 belongs with Amyrmex Kusnezov, 1953 to a monophyletic clade on the basis of the molecular phylogeny of the recently reassessed subfamily Dorylinae Leach, 1815 (Brady et al. 2014). This clade was formerly recognized as a distinct subfamily, Leptanilloidinae Baroni Urbani et al., 1992, and also comprises a third genus, Asphinctanilloides Brandão et al., 1999, for which no DNA sequences are yet available. 
Leptanilloides comprises 14 species of subterranean ants, including two species described as new in this paper, with morphological and behavioral traits distinctive of the army ant syndrome, including synchronization of larva production, brood carrying by workers under their mesosoma, nomadic habits, and a subdichthadiiform gyne (Brandão et al. 1999; Donoso et al. 2006; Borowiec \& Longino 2011). They present an apparent disjunctive distribution with the majority of species infrequently collected from Mexico to Bolivia, at altitudes of between 440 and 3350 m (Brandão et al. 1999; Longino 2003; Donoso et al. 2006; Ward 2007; Ward \& Brady 2009; Borowiec \& Longino 2011), and a single species, L. atlantica Silva et al., 2013, only known from its type locality at $800 \mathrm{~m}$ in south-eastern Brazil, more than $2500 \mathrm{~km}$ away from the other species (Silva et al. 2013). However, this distribution pattern is suspected to be the result of the insufficient or inadequate collecting effort applied to the soil environment (Silva et al. 2013). Our knowledge concerning the diversity and distribution of this genus is indeed very low: most species are only known from their type locality, one species from just two sites (L. gracilis Borowiec \& Longino, 2011 from Mexico and Guatemala; Borowiec \& Longino 2011), and two species from three localities (L. mckennae Longino, 2003 in Costa Rica (AntWeb 2015a); L. biconstricta Mann, 1923 from Bolivia (Mann 1923), Colombia (Zabala et al. 2006) and Venezuela (AntWeb 2015b)).

Borowiec \& Longino (2011) updated the diagnosis of the genus based on the worker caste. They described the state of 38 morphological variables and discussed the variability observed for some of them within the genus. In particular, they noted the presence, albeit reduced, of a metatibial gland in two species (L. erinys Borowiec \& Longino, 2011 and L. nubecula Donoso et al., 2006). This observation was interesting because this gland is considered to be a synapomorphy of Dorylinae in relation to Formicidae (Bolton 1990; 2003) but was estimated to be secondarily absent in Leptanilloides (Brandão et al. 1999; Bolton 2003; Longino 2003; Brady \& Ward 2005; Donoso et al. 2006).

Morphological data seem to support the segregation of Leptanilloides into two natural species-groups (Borowiec \& Longino 2011): the Leptanilloides biconstricta species-group, easily recognizable for the completely unfused promesonotal connection and the postpetiole nearly as high as the following abdominal segment, and the Leptanilloides legionaria species-group, with ants that have a partially to completely fused promesonotal connection and a reduced and isolated postpetiole. Importantly, the phylogeny of Brady et al. (2014) inferred from 11 nuclear DNA markers also supports this distinction (but only five Leptanilloides species were included in their work). In this paper, we provide a formal diagnosis of both species-groups.

The male caste has only been described for two species of the L. legionaria species-group, namely L. mckennae (Ward 2007) and L. nubecula (Donoso et al. 2006). In addition, Borowiec \& Longino (2011) described three males without associating them with workers or giving them specific names. The first male (called 'Male 1' in Borowiec \& Longino 2011) was suspected to belong to L. gracilis, a species from the L. biconstricta species-group, because of sympatric distribution, similar abundance, small size and the presence of two simple spurs on mid and hind tibia in both 'Male 1' and workers of L. gracilis. However, because several Leptanilloides species can occur in sympatry (Donoso et al. 2006; Borowiec \& Longino 2011), the association was cautiously not formalized without further evidence. No hypotheses were proposed concerning the identities of the two other males. It is noteworthy that males are also known for Amyrmex (Ward \& Brady 2009), but not for Asphictanilloides.

Boudinot (2015) indicated that most males of Dorylinae are uniquely identified by the bidentate or pronged ninth abdominal sternite (subgenital plate), the lack of pygostyles, and the poorly developed clypeus. Males of Leptanilloides and Amyrmex are highly derived and are identifiable by the following combination of characters: antennal torulus abutting or very nearly abutting anterior clypeal margin, oblique mesopleural sulcus absent, four closed cells present on forewing, and cinctus between abdominal pre- and postsclerites IV absent (Boudinot 2015; see also Ward \& Brady 2009). Moreover, the posterior 
margin of abdominal sternite IX is broad and deeply concave but not bifurcate (Ward 2007; Borowiec \& Longino 2011).

Here we describe the worker caste of two new Leptanilloides species belonging to the L. biconstricta species-group. A male with a unique mandible shape is also described, although we do not intend to formally name it until further information regarding its associated worker caste has been acquired. We also provide COI barcodes for the two new species and for this male. The key of Borowiec \& Longino (2011) to the worker caste is updated to include our two new species as well as the recently described L. atlantica Silva et al., 2013. Finally, we provide evidence of a metatibial gland in one of our species and note the hitherto unnoticed occurrence of a pectinate spur on the midtibia in some species.

\section{Material and methods}

\section{Molecular analyses}

One hindleg was sampled from 4 specimens (specimen codes of $L$. prometea sp. nov. workers: 4052302 , 4052314; code of L. copalinga sp. nov. worker: 4006302; code of the unassociated male: 4870101), and DNA was extracted with the NucleoSpin Tissue Kit (Macherey-Nagel, Germany) following the manufacturer's protocol. Moreover, the total genomic DNA was isolated from the complete body of 4 workers of L. prometea sp. nov. (specimen codes 4052311, 4052312, 4060602, and 4060603) also using the NucleoSpin Tissue Kit. After DNA extraction, these 4 specimens were preserved as vouchers in $96 \%$ ethanol. PCR amplification of the 5 ' end of the cytochrome $c$ oxidase subunit I (COI) marker (standard DNA barcode region) was performed with the primers LCO1490 and HCO2198 (Folmer et al. 1994). The wingless wnt-1 gene (Wg) was amplified using primers Wg578F (Ward \& Downie 2005) and Wg1032R (Abouheif \& Wray 2002). PCR conditions were the same as in Delsinne et al. (2012). Amplicons were directly sequenced in both directions and aligned with all $\mathrm{COI}$ and $\mathrm{Wg}$ sequences of Leptanilloides and Cylindromyrmex Mayr, 1870 (as outgroup) available in GenBank and in BOLD, the Barcode of Life Data System (Ratnasingham \& Hebert 2007). We obtained COI sequences for 6 specimens of L. prometea sp. nov., 1 of L. copalinga sp. nov., and 1 of the unnamed Leptanilloides male. Unfortunately, we obtained only one $\mathrm{Wg}$ sequence for $L$. prometea $\mathrm{sp}$. nov. (specimen code 4052311; Appendix 1). Mega ver. 6.06 (Tamura et al. 2013) was used to perform alignments with the Clustal W algorithm (Thompson et al. 1994), calculate pairwise uncorrected p-distances and construct neighbor-joining trees with bootstrapping (1000 replicates).

All COI and Wg sequences were deposited in GenBank with accession numbers KT601697KT601704 (COI) and KT750331 (Wg). Process IDs of specimens in BOLD are from LEPEC001-15 to LEPEC007-15 and LEPEC009-15. Further phylogenetic analyses were performed on the basis of the Wg DNA dataset (Appendix 1), which included sequences representing more species than the COI dataset. Parsimony trees were calculated in R using the packages ape (Paradis et al. 2004) and phangorn (Schliep 2011) with 1000 bootstrap replicates (non-parametric bootstrapping) (Appendix 2). Best partitioning schemes and best-fit substitution models were estimated using PartitionFinder ver. 1.0 (Lanfear et al. 2012) in order to perform maximum likelihood analysis and Bayesian inference of phylogeny. Two partitions (one partition for the third codon position and one partition for the two other positions) were selected, with best-fit substitution models TIM+Gamma (Posada 2003) and JC (Jukes \& Cantor 1969), respectively (using the Bayesian information criterion). Maximum likelihood analysis was conducted using GARLI ver. 2.0 (Zwickl 2006) with a bootstrapping test (500 replicates) (Appendix 3). Bayesian inference was performed with MrBayes ver. 3.2.3 (Ronquist et al. 2012; Appendix 1). Two parallel runs, with four chains each, were run for ten million generations, with unlinked nucleotide substitution parameters for each data partition. Every $1000^{\text {th }}$ generation was sampled, convergence of the Markov chains was monitored, average standard deviation of split frequencies decreased below 0.01, and traces of the parameters were checked using Tracer ver. 1.6 (Rambaut et al. 2014) following 
the recommendations of Ronquist et al. (2011), Lesaffre \& Lawson (2012) and SAS Institute (2009). Finally, the first $25 \%$ of the trees were discarded ("burn-in") to summarize the tree samples.

\section{Images}

High resolution digital images were taken using either a Leica DFC290 camera attached to a Leica Z6APO stereo microscope or a Leica MC170 camera attached to a Leica S8APO stereo microscope. A series of images was taken by focusing the sharpness on different levels of the specimen, using the Leica Application Suite ver. 38 (2003-2011) and combined with the stacking software Combine ZP (Hadley 2010). Final editing of the images was done in Adobe Photoshop CS5. SEM photographs of the specimens (spm 4006301 and spm 4052301 for L. copalinga sp. nov. and L. prometea sp. nov., respectively) were taken at the Royal Belgian Institute of Natural Sciences using a FEI Quanta 200 scanning electron microscope (SEM).

\section{Measurements}

Measurements were made using an Olympus SZ61 stereo microscope at a magnification of $45 \times$ with a micrometer. All the measurements are presented in millimeters. The following abbreviations are used:

$\mathrm{HL}=$ Head length, measured in full face view, from anterior edge of frontal lobes (therefore without including clypeal lamella) to posterior border of head

$\mathrm{HW}=$ Head width, maximum width of head measured in full face view; HW for males includes eyes (workers eyeless)

$\mathrm{SL}=$ Scape length, excluding basal condyle and neck

LAII, LAIII, LAIV, LAXIII = Length of second, third, fourth and terminal $\left(13^{\text {th }}\right)$ antennal segments, respectively (male only)

$\mathrm{EL}=$ Eye length, measured in full face view, maximum length of eye parallel to midline (male only)

$\mathrm{MaL}=$ Mandible length, measured in full face view, length of line running medially from clypeal anterior margin to mandible apex (male only)

PrW = Pronotal width, maximum width in dorsal view

$\mathrm{WL}=$ Weber's length, measured from anterior edge of pronotum to posterior edge of metapleural lobe; this measure called Mesosoma Length (ML) in Borowiec \& Longino (2011) and Silva et al. (2013)

$\mathrm{MH}=$ Mesosoma height: in lateral view, maximum height measured from lowermost point of mesopleuron (in front of middle coxa) to dorsal edge of mesosoma, measured perpendicularly to long axis of mesosoma

$\mathrm{PL}=$ Petiole length, maximum length of the petiole measured in dorsal view, starting at base of anterior face and ending at base of posterior edge

$\mathrm{PW}=$ Petiole width, maximum width of petiole measured in dorsal view

PPL = Postpetiole (= third abdominal segment) length, maximum length of node measured in dorsal view

PPW $=$ Postpetiole width, maximum width of node measured in dorsal view

AivL $=$ Length of fourth abdominal segment, in dorsal view

AivW = Maximum width of fourth abdominal segment, in dorsal view

$\mathrm{FFeL}=$ Maximum length of fore femur, measured along extensor (outer) surface

$\mathrm{FFeW}=$ Maximum width in lateral view of fore femur

$\mathrm{HFeL}=$ Length of hind femur, measured along extensor (outer) surface

HTL = Length of hind tibia, measured along extensor (outer) surface

$\mathrm{CI}=$ Cephalic index, $\mathrm{HW} / \mathrm{HL} \times 100$

$\mathrm{SI}=$ Scape index, SL $/ \mathrm{HL} \times 100$

PI $=$ Petiolar index, $\mathrm{PW} / \mathrm{PL} \times 100$ 


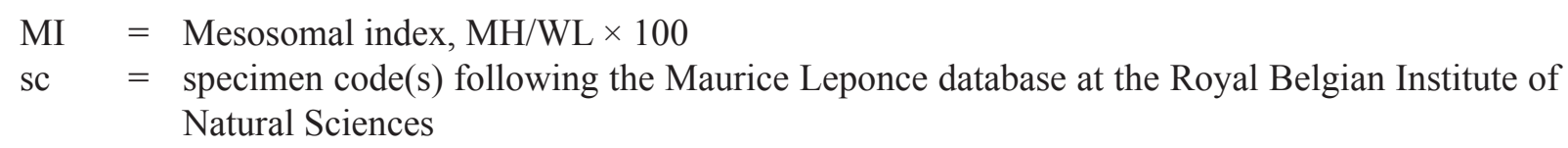

For consistency, we follow Borowiec \& Longino (2011) for terminology, in particular for wing venation and genitalia.

\section{Deposition of material}

Holotypes and paratypes have been deposited at:

BMNH $=$ British Museum of Natural History (Natural History Museum), London, UK

CASC $=$ California Academy of Sciences, San Francisco, CA, USA

ICN $=$ Insect Collection, Instituto de Ciencias Naturales, Universidad Nacional de Colombia, Bogotá D.C., Colombia

JTLC = John T. Longino, personal collection, University of Utah, Salt Lake City, UT, USA

MCZC = Museum of Comparative Zoology, Harvard University, Cambridge, Massachusetts, USA

MUTPL = Museo de Colecciones Biológicas de la Universidad Técnica Particular de Loja, Loja, Ecuador

MZSP = Museu de Zoologia da Universidade de São Paulo, São Paulo, Brazil

QCAZ = Museum of Zoology of the Pontificia Universidad Católica del Ecuador, Quito, Ecuador

RBINS $=$ Royal Belgian Institute of Natural Sciences, Brussels, Belgium

\section{Results}

Class Hexapoda Blainville, 1816

Order Hymenoptera Linnaeus, 1758

Suborder Apocrita Latreille, 1810

Infraorder Aculeata Latreille, 1802

Superfamily Vespoidea Latreille, 1802

Family Formicidae Latreille, 1809

Subfamily Dorylinae Leach, 1815

Genus Leptanilloides Mann, 1823

\section{Diagnosis of the Leptanilloides biconstricta species-group}

Species from the Leptanilloides biconstricta species-group possess the typical characters of the genus (see diagnosis in Borowiec \& Longino 2011) but can be grouped by the fact that they share the following criteria: promesonotal connection completely unfused and flexible; lateroclypeal tooth (called genal tooth in Brandão et al. 1999, Longino 2003 and Donoso et al. 2006) well-developed (although apparently lacking in L. caracola Donoso et al., 2006, a species known only by its holotype; because this criterion may be difficult to observe with a stereo microscope, even at high magnification, the absence of a lateroclypeal tooth in L. caracola should be confirmed in SEM); abdominal segment III (postpetiole) nearly as high as abdominal segment IV; and postpetiolar spiracle situated proximately to the anterior margin of the tergite.

Moreover, species from this group are generally smaller than species of the L. legionaria species-group (Fig. 1).

This group includes the ten following species:

L. atlantica Silva et al., 2013

L. biconstricta Mann, 1923 
L. caracola Donoso et al., 2006

L. copalinga Delsinne \& Donoso sp. nov.

L. erinys Borowiec \& Longino, 2011

L. femoralis Borowiec \& Longino, 2011

L. gracilis Borowiec \& Longino, 2011

L. improvisa Brandão et al., 1999

L. prometea Delsinne \& Donoso sp. nov.

L. sculpturata Brandão et al., 1999

\section{Diagnosis of the Leptanilloides legionaria species-group}

Species from the Leptanilloides legionaria species-group possess the characters of the genus (see diagnosis in Borowiec \& Longino 2011) but are grouped because they share the following criteria: promesonotal connection at least partially fused; lateroclypeal tooth absent or reduced; postpetiole reduced and isolated; and postpetiolar spiracle shifted posteriad on anteromedian side of the tergite.

This group includes the following four species:

L. legionaria Brandão et al., 1999

L. mckennae Longino, 2003

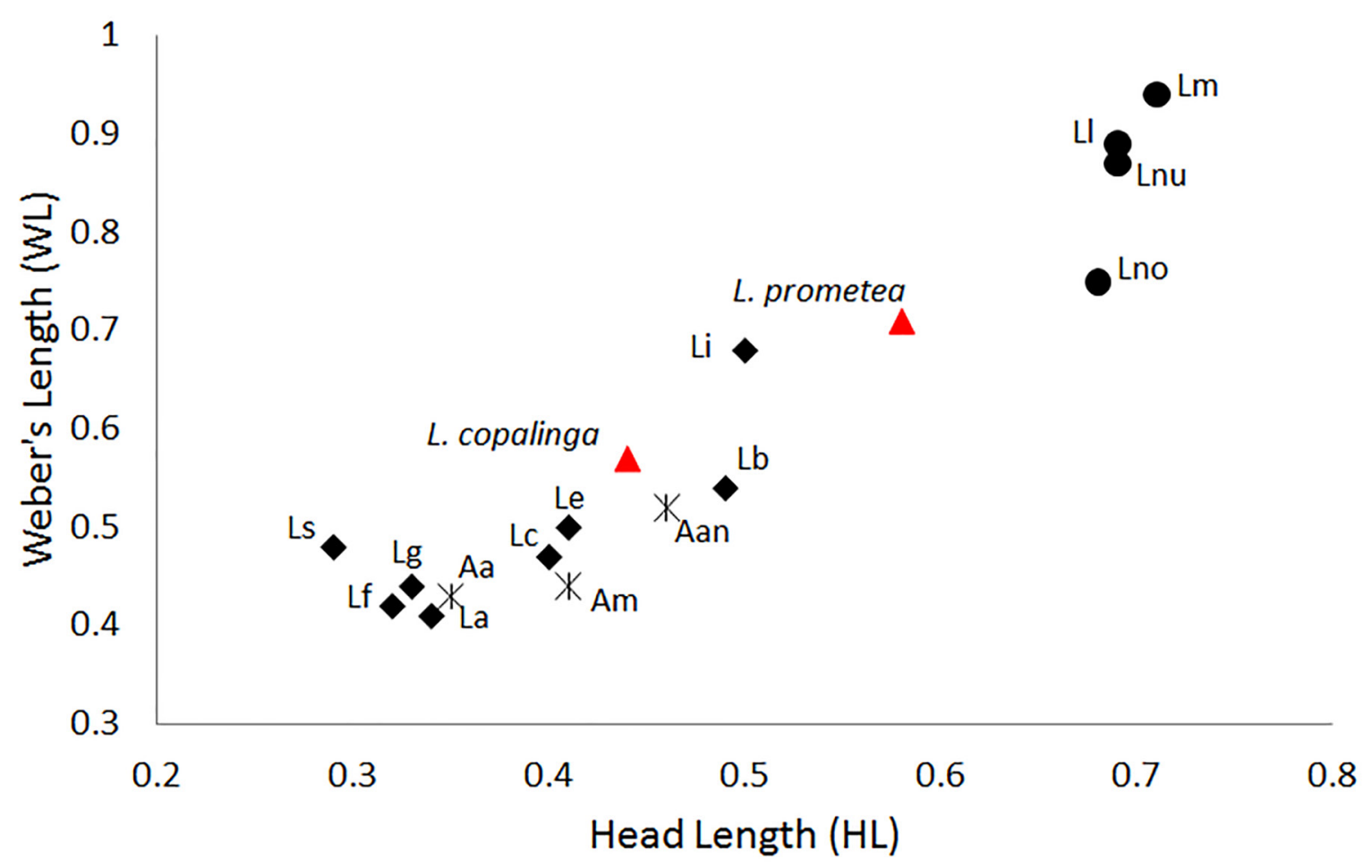

Fig. 1. Relationship between HL and WL among workers in species of Leptanilloides and Asphinctanilloides. Specimens measured are holotypes or paratypes. Measurements are in $\mathrm{mm}$. WL is called Mesosoma Length (ML) in Borowiec \& Longino (2011) and Silva et al. (2013). Triangles: the two Leptanilloides described in this paper (L. copalinga Delsinne \& Donoso sp. nov. and L. prometea Delsinne \& Donoso sp. nov.); diamonds: Leptanilloides biconstricta species-group (La: L. atlantica, Lb: L. biconstricta, Lc: L. caracola, Le: L. erinys, Lf: L. femoralis, Lg: L. gracilis, Li: L. improvisa, Ls: L. sculpturata); dots: Leptanilloides legionaria species-group (L1: L. legionaria, Lm: L. mckennae, Lno: L. nomada, Lnu: L. nubecula); stars: Asphinctanilloides species (Aa: A. amazon Brandão et al., 1999, Aan: A. anae Brandão et al., 1999, Am: A. manauara Brandão et al., 1999). 
L. nomada Donoso et al., 2006

L. nubecula Donoso et al., 2006

\section{Key to workers of Leptanilloides}

1. Abdominal segment III (postpetiole) in lateral view much smaller than adjoining fourth abdominal segment. Spiracle of segment III shifted posteriad on anteromedian side of tergite. Body size relatively large, HL $0.68-0.75$ (Fig. 1) ...............2 (L. legionaria species-group)

- Abdominal segment III (postpetiole) in lateral view nearly as high as abdominal segment IV. Spiracle of segment III situated forward on the tergite. Body size relatively small, HL 0.31-0.62 (Fig. 1) .......................................................5 (L. biconstricta species-group)

2. Head subquadrate, CI 85-88; lateral margin nearly straight and parallel. Propodeal declivity short and vertical, propodeum with dorsal and posterior faces clearly differentiated (Ecuador) .........

L. nomada Donoso et al., 2006

- Head subrectangular, CI 75-83; lateral margin convex. Propodeal declivity usually rounded

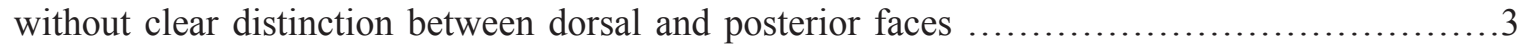

3. Head sculpture less dense, at most 10-12 shallow foveolae across face at midlength. Lateral margin of head distinctly convex. Lateroclypeal tooth present. Posterior margin of head slightly concave (Colombia) L. legionaria Brandão et al., 1999

- Head sculpture denser, with at least 15 foveolae across face at midlength. Lateral margin of head slightly convex. Lateroclypeal tooth absent. Posterior margin of head deeply concave ...........4

4. Legs shorter, HW/HTL $\times 100>78$. Hypostomal tooth present (Ecuador)

L. nubecula Donoso et al., 2006

- Legs longer, HW/HTL $\times 100<78$. Hypostomal tooth absent (Costa Rica)

L. mckennae Longino, 2003

5. Lateroclypeal tooth absent. Masticatory margin of mandible edentate (Ecuador)

.L. caracola Donoso et al., 2006

- Lateroclypeal tooth present. Masticatory margin of mandible dentate (at least minute denticles present)

6. In lateral view, abdominal segment IV narrowly attached to preceding segment III and broadly to succeeding segment $\mathrm{V}$, with contrast between widths of anterior and posterior articulations

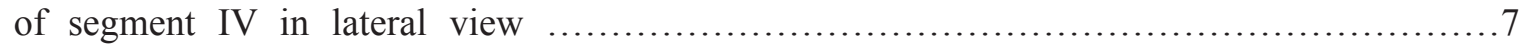

- In lateral view, abdominal segment IV relatively broadly attached to preceding segment III, with little contrast between widths of anterior and posterior articulations of segment IV in

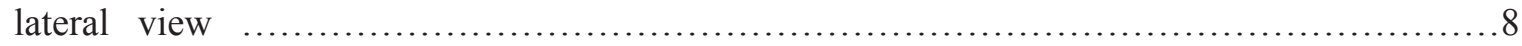

7. In lateral view, sternite of abdominal segment III evenly rounded, making sternal and tergal portions subequal. Petiole as long as postpetiole. Reticulation on mesopleuron and metapleuron uninterrupted. Head densely foveolate, with $c$. 20-30 foveolae covering a straight transverse line at head midlength. $\mathrm{HL} \leq 0.36$ (Brazil) .......................... atlantica Silva et al., 2013

- In lateral view, sternite of abdominal segment III (postpetiole) distinctly bulging anteriorly, making sternal portion of segment deeper than tergite (Borowiec \& Longino 2011: fig. 2d). Petiole longer than postpetiole (Borowiec \& Longino 2011: fig. 2d). Reticulation on mesopleuron and metapleuron superficial and interrupted. Head sculpture less dense, with only 10-20 foveolae covering a straight transverse line at head midlength. $\mathrm{HL}=0.49$ in only measured specimen (Bolivia, Colombia, Venezuela) L. biconstricta Mann, 1823 


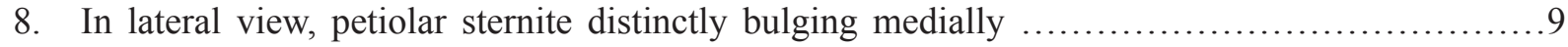

- In lateral view, petiolar sternite straight (not bulging) or bulging anteriorly $\ldots \ldots \ldots \ldots \ldots \ldots \ldots \ldots$

9. Hindtibia with two very small, simple spurs, without pectinate spur clearly visible under $50 \times$ magnification. Petiolar spiracle opening in an excavation distinctly larger than propodeal spiracle (Borowiec \& Longino 2011: fig. 5g-h). Flange over metapleural gland opening sharply pointed posteriorly (Mexico, Guatemala) ........................ gracilis Borowiec \& Longino, 2011

- Hindtibia with large pectinate spur, clearly discernable under 50× magnification. Petiolar spiracle not in excavation, similar and subequal to or smaller in diameter than propodeal spiracle (Borowiec \& Longino 2011: fig. 4g-h). Flange over metapleural gland opening rounded posteriorly (Venezuela) L. femoralis Borowiec \& Longino, 2011

10. Head narrow, $\mathrm{HL}<0.30$, HW $<0.20$, CI $<60$. Head dorsum densely foveolate with foveolae separated by less than their diameter, often contiguous (Colombia)

L. sculpturata Brandão et al., 1999

- Head broader, HL $>0.30, \mathrm{HW}>0.20, \mathrm{CI}>65$. Head dorsum less densely foveolate, with foveolae separated by about their diameter or more ...................................... 11

11. Size large, $\mathrm{HL} \geq 0.50, \mathrm{HW} \geq 0.38$. Flange over metapleural gland opening short, not surpassing propodeum declivity margin in lateral view, and rounded posteriorly ..12

- Smaller, HL $<0.45$, HW $<0.35$. Flange over metapleural gland opening long, surpassing propodeum declivity margin in lateral view, and sharply pointed posteriorly $\ldots \ldots \ldots \ldots \ldots \ldots . . .13$

12. $\mathrm{HL}=0.50$ on single known specimen. Masticatory margin of mandible distinctly dentate, with regularly spaced and well-developed teeth (Brandão et al. 1999: fig. 16) (Ecuador)

L. improvisa Brandão et al., 1999

- $\quad H L \geq 0.58$. Masticatory margin of mandible dentate but teeth extremely minute, blunt and irregularly shaped, difficult to discern even under magnifications of about 100× (Figs 4B, 6C) (Ecuador) L. prometea Delsinne \& Donoso sp. nov.

13. Ventral margin of petiolar sternite forming an even convexity in lateral view. Reticulation on mesopleuron, metapleuron and lateral side of petiole uninterrupted. In dorsal view, petiole subquadrate, $67 \leq \mathrm{PI} \leq 80$ (Ecuador) L. erinys Borowiec \& Longino, 2011

- Ventral margin of petiolar sternite relatively straight in lateral view (Fig. 3C). Reticulation on mesopleuron, metapleuron and lateral side of petiole superficial and interrupted. In dorsal view, petiole slender, rectangular, $52 \leq \mathrm{PI} \leq 63$ (Fig. 3D) (Ecuador)

L. copalinga Delsinne \& Donoso sp. nov.

Leptanilloides copalinga Delsinne \& Donoso sp. nov. urn:1sid:zoobank.org:act:4324B13A-500B-464C-AE3F-62BCAF95A2CC

Figs $2 \mathrm{~A}-\mathrm{F}, 3 \mathrm{~A}-\mathrm{F}$

\section{Diagnosis}

Leptanilloides copalinga sp. nov. belongs to the L. biconstricta species-group. It can be distinguished from other species of this group by the combination of the following characters: masticatory margin of mandible feebly dentate, with teeth extremely minute, blunt and irregularly shaped (Fig. 3A); lateroclypeal tooth present (difficult to observe in stereo microscopy even at high magnification due to the small size of the species but obvious in SEM; Fig 3A); head with piligerous foveolae separated by smooth interspaces equaling 2-3 diameters; reticulation on mesopleuron, metapleuron and lateral side of petiole superficial and interrupted; flange over metapleural gland opening conspicuous and sharply 
pointed posteriorly, resulting in a projection which surpasses propodeum declivity margin in lateral view (Fig. 3B); petiole slender in dorsal view, $52 \leq \mathrm{PI} \leq 63$ (Fig. 3D); and subpetiolar process straight (not distinctly bulging), with a rounded projection anteriorly (Fig. 3C).

\section{Etymology}

Name in apposition which refers to the Copalinga Private Reserve, the type locality, in honour of its owners Catherine Vits and Boudewijn de Roover to acknowledge their efforts for the conservation of Ecuadorian biodiversity.

\section{Type material}

\section{Holotype}

ECUADOR: Worker, Zamora-Chinchipe Prov., Copalinga Private Reserve, 1510 m, 44'56.6" S, 78 58'5.71" W, 2 Apr. 2010, soil sample, coll. Thibaut Delsinne and Tania Milena Arias-Penna (QCAZ, sc 4006304).

\section{Paratypes}

ECUADOR: Same data as holotype: 1 worker, gold-coated for SEM (RBINS, sc 4006301); 1 pinned (MUTPL, sc 4006303); 1 worker, 96\% ethanol (RBINS, sc 4006302, specimen with DNA data). GenBank accession number: KT601697.

\section{Measurements (in $\mathbf{m m}$ ) and indices}

Holotype (paratype 4006303): HW 0.33 (0.34), HL 0.44 (0.44), SL 0.23 (0.21), PrW 0.2 (0.22), WL 0.56 (0.57), MH 0.17 (0.17), PL 0.17 (0.18), PW 0.09 (0.11), PPL 0.16 (0.18), PPW 0.16 (0.18), AivL 0.26 (0.26), AivW 0.3 (0.33), FFeL 0.23 (0.27), FFeW 0.09 (0.11), HFeL 0.29 (0.29), HTL 0.3 (0.29), CI 75 (76.25), SI 70 (60.66), PI 51.61 (62.5), MI 30 (30.39).

\section{Description}

\section{Worker}

With the characters typical of the genus (see diagnosis and description in Brandão et al. 1999 and Borowiec \& Longino 2011) and of the L. biconstricta species-group (see diagnosis of the group above). Other characters or differences are as follows:

HEAD. Elongate and rectangular with lateral margin nearly straight and parallel. Posterior corner rounded. Posterior margin modestly convex, almost straight. Parafrontal ridge absent. Clypeal lamella strongly convex (Fig. 3A). Basal and masticatory margins of mandible dentate but teeth extremely minute, blunt and irregularly shaped, difficult to discern even under magnifications of about $100 \times$ (Fig. 3A). Basal and masticatory margins united by a broad convexity. Basal margin faintly crenulate. Labial and maxillary palps difficult to discern in situ but formula apparently 2,2. Hypostomal anterior border without distinct tooth. Scape when laid back failing to reach medial distance to posterior margin of head by nearly one maximum diameter.

Mesosoma. Flange over metapleural gland opening conspicuous and sharply pointed posteriorly, forming a projection which surpasses propodeum declivity margin (Fig. 3B). Femur not conspicuously enlarged, relatively slender. Midtibia with one short (i.e., half size of foretibia strigil), pectinate spur (Fig. 3F), although pectination may be difficult to observe even at high magnification. Hindtibia with one broadly pectinate spur roughly as long as strigil. Metatibial gland absent or very reduced and not visible even in SEM.

Metasoma. Long and relatively slender. In dorsal view, petiole rectangular with lateral margin slightly convex, twice as long as wide (Fig. 3D), and as long as abdominal segment III (postpetiole). Anterior 
face concave, posterior face straight. In lateral view, petiole height approximately $1 / 4$ smaller than height of abdominal segment III. Petiolar tergite dome-shaped, with short anterior and posterior faces, maximum height situated in posterior half. Short tubulated portion present posteriorly. Petiolar spiracle inconspicuous, not in excavation, set near anterior rim of tergite, similar in form and slightly smaller in diameter than propodeal spiracle. Subpetiolar process with ventral margin straight to slightly concave, not distinctly bulging, anteriorly forming rounded projection (Fig. 3C). Maximum height of petiolar sternite situated medially. In dorsal view, abdominal segment III (postpetiole) trapezoid, with straight, parallel anterior and posterior faces. Posterior face twice as long as anterior face. In lateral view, tergite evenly convex, without well-differentiated posterior face. Sternite evenly rounded. In dorsal view, abdominal segments IV-VI subequal in length.

Pilosity And sculpture. Mandible smooth and shiny, with few, scattered piligerous punctures. Head with abundant deep piligerous foveolae and smooth interspaces on average equaling two or three puncture diameters. Mesosoma and abdomen more finely and sparsely punctate. Fine reticulate sculpture present laterally on lower pronotum, mesopleuron, propodeum and petiole. Dorsal part of pronotum, mesopleuron, propodeum and petiole smooth and shiny. Body and appendages with abundant, short and subdecumbent to suberect hairs. Body color yellow to reddish (Fig. 2), with head and mesosoma darker than petiole and gaster. Legs and antennae yellowish.

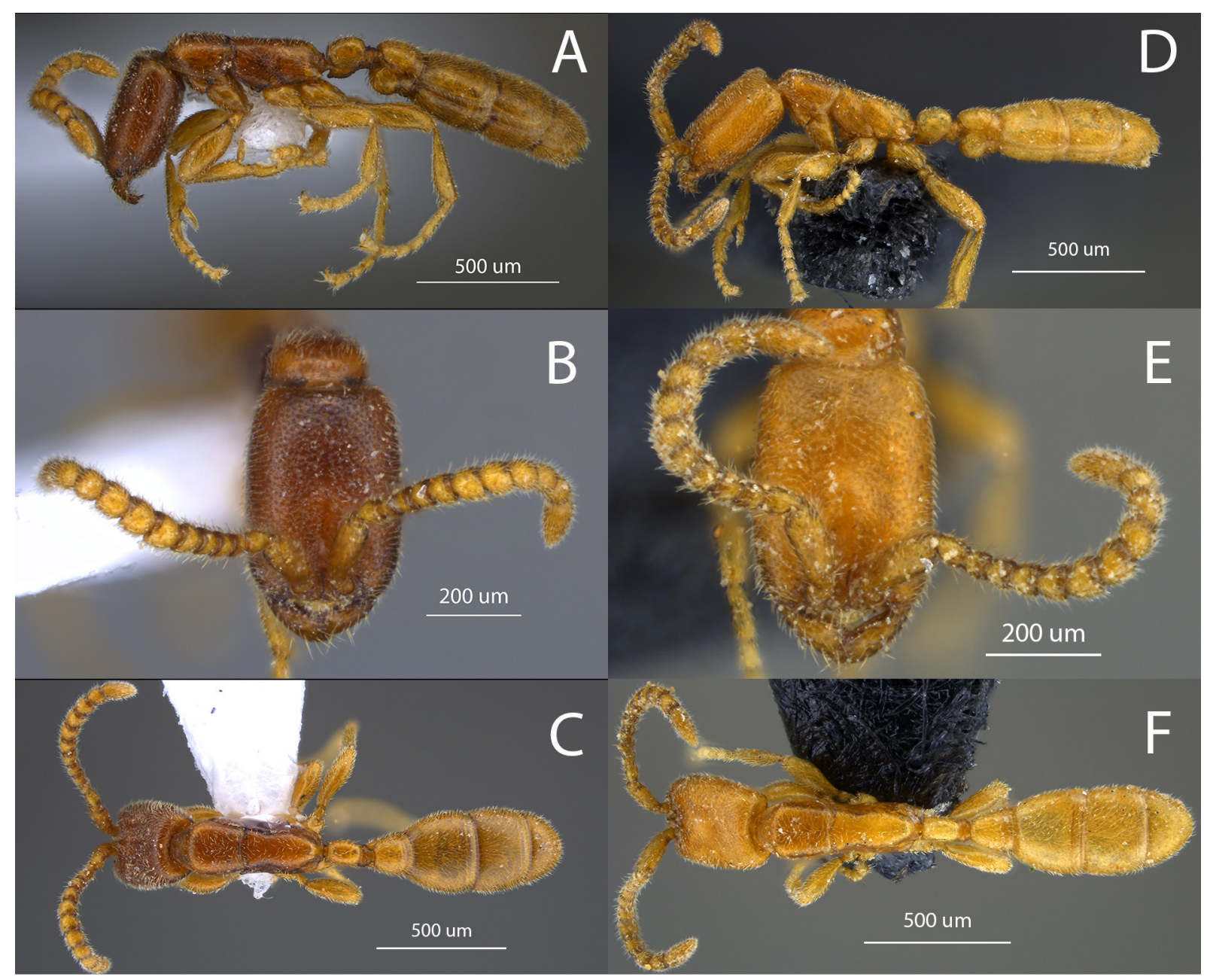

Fig. 2. Leptanilloides copalinga Delsinne \& Donoso sp. nov. A-C. Paratype worker (specimen code 4006302). D-F. Holotype worker (specimen code 4006304). A, D. Habitus, dorsal view. B, E. Head in full-face view. C, F. Habitus, lateral view. 


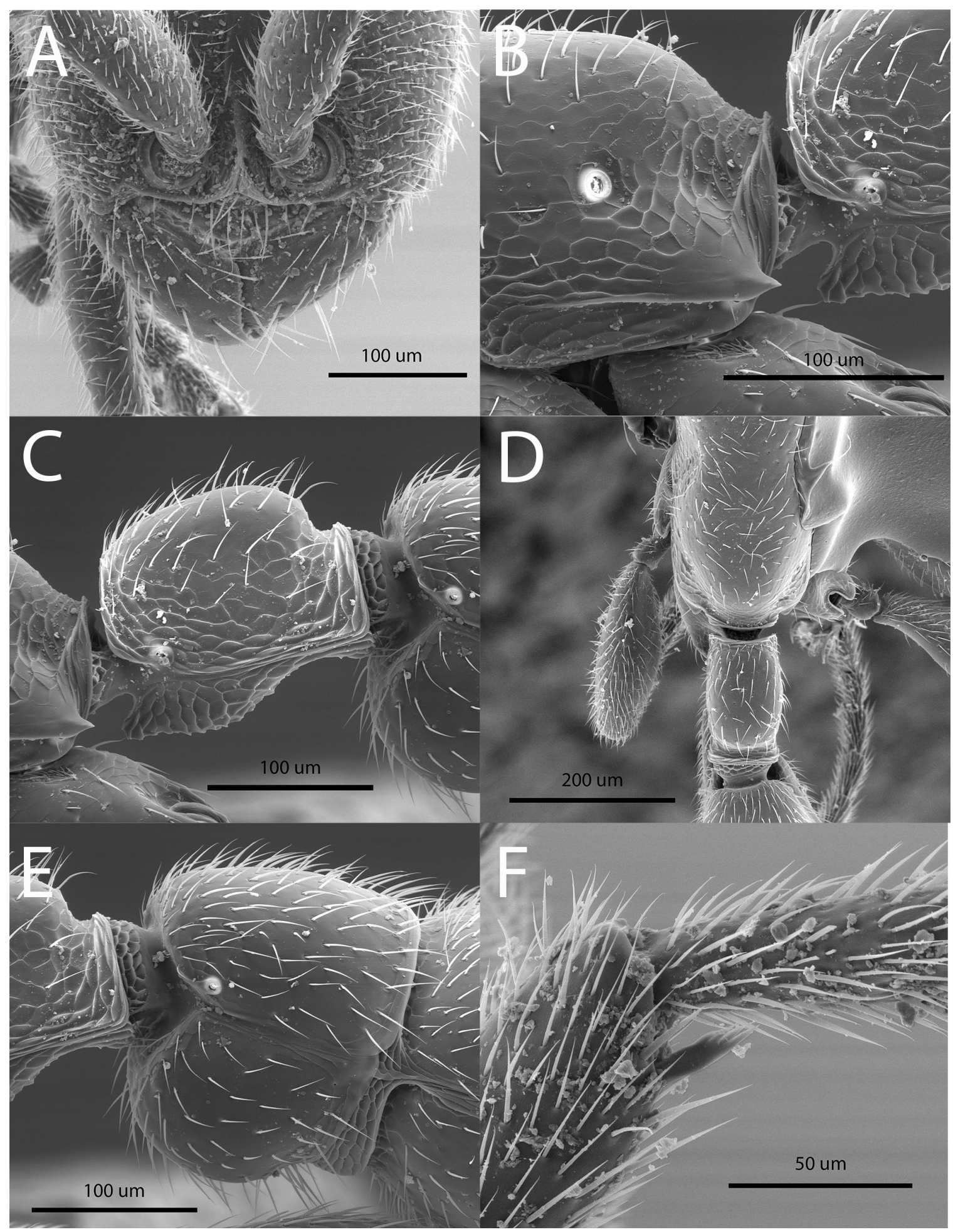

Fig. 3. Leptanilloides copalinga Delsinne \& Donoso sp. nov. Paratype worker (specimen code 4006301). A. Anterior part of the head in full-face view, showing vertical and fused frontal carinae, exposed antennal socket, lateroclypeal tooth, strongly convex clypeal lamella and subtriangular mandible with minute denticles along its inner margin. B. Lower part of propodeum in lateral view, showing the long and sharp flange over the metapleural gland opening. C. Petiole in lateral view. D. Propodeum and petiole in dorsal view. E. Abdominal segment III (postpetiole) in lateral view. F. Mesotibial spur, short and pectinate. 


\section{Gyne \\ Unknown. \\ Male \\ Unknown.}

\section{Distribution}

Only known from the type locality.

\section{Biology}

Unknown. The type series was found by visual search in a $15 \times 15 \times 15 \mathrm{~cm}$ soil core inspected for ants during 20 person-minutes (the soil content was examined over a white plastic board using a headlamp to facilitate ant detection), which suggests subterranean habits as observed in other Leptanilloides species. The habitat is a relatively well-preserved evergreen lower montane forest. Soil texture is clay loam; proportion of sand, silt and clay is $44 \%, 22 \%$, and $35 \%$, respectively; mean $\mathrm{pH}=4 \pm 0.2 \mathrm{SD}(\mathrm{n}=24$ soil samples).

\section{Remarks}

This species belongs to the L. biconstricta species-group. The most similar species are L. biconstricta and $L$. atlantica, which also possess a long and sharply pointed flange over the metapleural gland opening and a straight (not bulging) petiolar sternite with a rounded anterior projection. However, these two species have a deeper constriction between the postpetiole and abdominal segment IV. Besides, L. copalinga sp. nov. has a petiole roughly as long as the postpetiole (longer in L. biconstricta) and its postpetiolar sternite is evenly rounded (distinctly bulging anteriorly in L. biconstricta). Finally, L. copalinga sp. nov. is larger than L. atlantica (Fig. 1). The other species of the L. biconstricta speciesgroup are easily distinguished from $L$. copalinga sp. nov. by, among other characters, the shape of their petiolar sternite (bulging medially in L. gracilis and L. femoralis; bulging anteriorly in L. erinys), the shape of the flange over the metapleural gland opening (short and rounded posteriorly in L. improvisa and L. prometea), the head sculpture (more densely foveolate in L. sculpturata) and the lateroclypeal tooth (absent in L. caracola).

Leptanilloides prometea Delsinne \& Donoso sp. nov. urn:1sid:zoobank.org:act:CC756523-8025-4C13-8987-5F91A1E04B7E

Figs 4A-D, 5, 6A-F, 7A-C

\section{Diagnosis}

Leptanilloides prometea belongs to the L. biconstricta species-group and can be distinguished by the combination of the following characters: masticatory margin of mandible dentate but teeth extremely minute, blunt and irregularly shaped (Fig. 6C); lateroclypeal tooth present (Fig. 6C); head with piligerous foveolae separated by smooth interspaces equaling, on average, puncture diameters; fine, uninterrupted reticulation on mesopleuron, metapleuron and lateral side of petiole; flange over metapleural gland opening forming a short, blunt projection (Fig. 6D); and subpetiolar process relatively straight (not distinctly bulging), without posterior angle (Fig. 6E).

\section{Etymology}

Name in apposition, in honour of the Prometeo initiative of the Ecuadorian government that seeks to strengthen research and knowledge transference by getting national and international experts to work together. This project is aligned to the Ecuadorian "National Development Plan for Good Living", which has the objective, among others, of guaranteeing the rights of Nature and promoting a healthy and 
sustainable environment. Furthermore, the species is the largest of the L. biconstricta species-group and its name nicely reminds us of 'Prometheus', the Titan in Greek mythology who brought fire, a symbol of enlightenment, to mankind. We hope that this new ant species will symbolize the promise of a bright future for Ecuadorian biodiversity.

\section{Type material}

\section{Holotype}

ECUADOR: Worker, Zamora-Chinchipe Prov., Reserva Biológica San Francisco (RBSF), 2070 m, $3^{\circ} 58^{\prime} \mathrm{S}, 79^{\circ} 05^{\prime} \mathrm{W}, 13$ May 2010, within $0.5 \mathrm{~m}^{2}$ of leaf litter extracted with a mini-Winkler apparatus for 96 h, coll. Thibaut Delsinne and Tania Milena Arias-Penna (QCAZ, sc 4267803).

\section{Paratypes $(n=67)$}

ECUADOR: Same data as holotype except that specimens were captured after $48 \mathrm{~h}$ of Winkler extraction: 30 workers, 96\% ethanol (RBINS, General Inventory Number 33044: sc 4052302 [1 specimen with DNA data], sc 4052314 [1 specimen with DNA data], sc 4052316 [21 specimens without DNA data]; BMNH [1 specimen, sc 4052317]; CASC [1 specimen, sc 4052318]; ICN [1 specimen, sc 4052319]; JTLC [1 specimen, sc 4052320]; MCZC [1 specimen, sc 4052321]; MZSP [1 specimen, sc 4052322]; QCAZ [1 specimen, sc 4052323]); 3 workers, pinned (MUTPL, sc 4052310, 4052315; RBINS, sc 4052313);

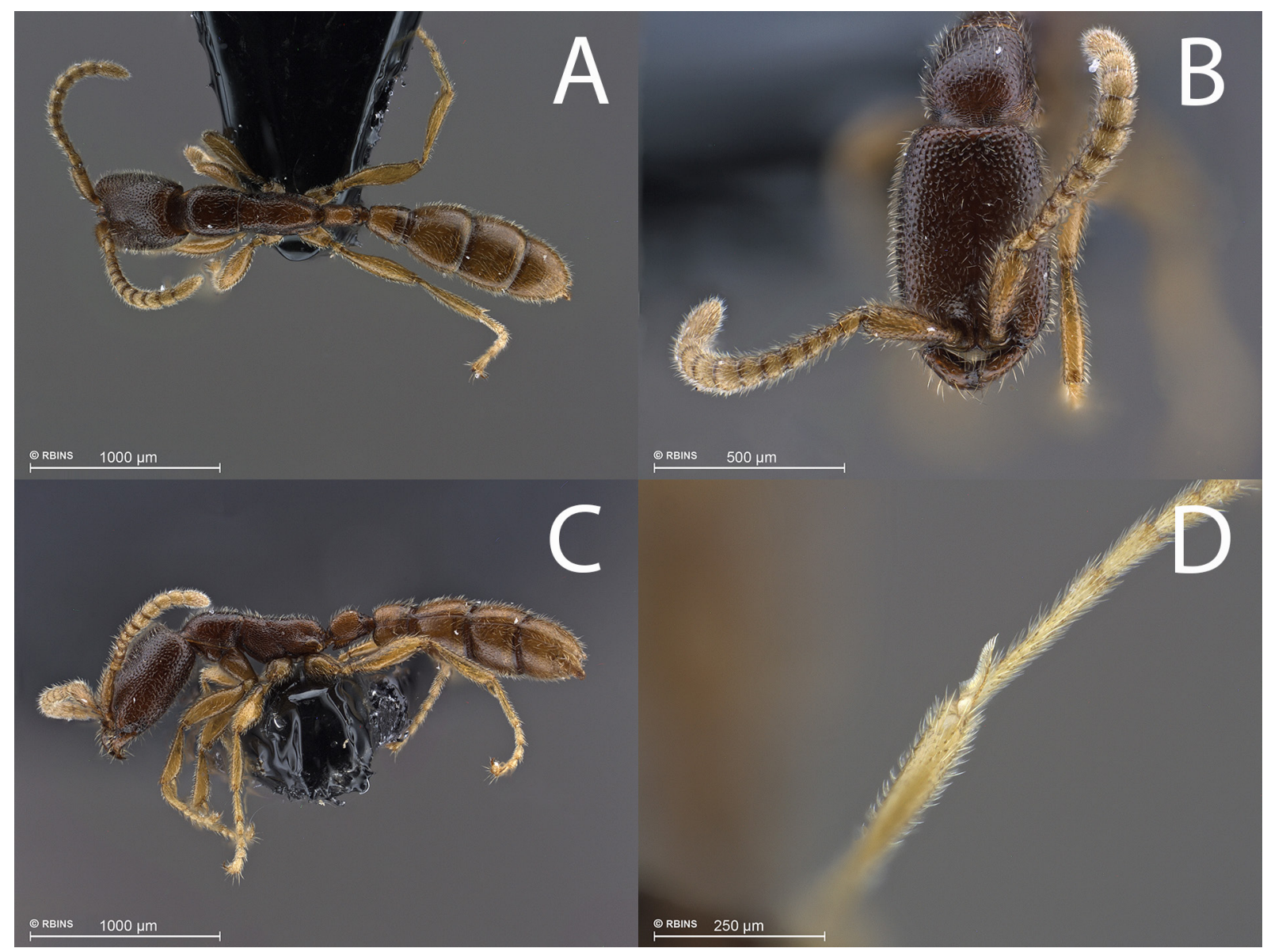

Fig. 4. Leptanilloides prometea Delsinne \& Donoso sp. nov. - A-C. Paratype worker (specimen code 4052301). A. Habitus, dorsal view. B. Head in full-face view. C. Habitus, lateral view. - D. Apex of hindtibia; reservoir of metatibial gland is visible under translucent cuticle at the base of the tibial spur (paratype, specimen code 4052313). 
2 workers, 96\% ethanol after non-destructive DNA extraction (RBINS, sc 4052311, 4052312); 1 worker, gold-coated for SEM (RBINS, sc 4052301). - Same data as holotype except 21 Mar. 2010, within upper $5 \mathrm{~cm}$ of organic layer of a core $(\varnothing 5 \mathrm{~cm})$ extracted by heat using a modified high gradient extractor for 4 days: 28 workers, $96 \%$ ethanol (RBINS, sc 4060601); 2 workers, 96\% ethanol after non-destructive DNA extraction (RBINS, sc 4060602, 4060603); 1 worker, pinned (MUTPL, sc 4060604). GenBank accession numbers: KT601698-KT601703 and KT750331.

\section{Measurements (in $\mathrm{mm}$ ) and indices}

Holotype (3 paratypes): HW 0.4 (0.4-0.44), HL 0.58 (0.61-0.62), SL 0.27 (0.29), PrW 0.27 (0.29), WL $0.71(0.76-0.78)$, MH 0.23 (0.24), PL $0.22(0.22-0.23)$, PW 0.11 (0.12), PPL $0.22(0.22-0.23)$, PPW 0.2 (0.22-0.23), AivL 0.31 (0.31-0.33), AivW 0.37 (0.38-0.4), FFeL 0.38 (0.38-0.4), FFeW 0.11 (0.11), HFeL 0.44 (0.44-0.45), HTL 0.42 (0.44-0.46), CI 69.23 (65.45-71.43), SI 66.67 (66.25-72.22), PI 50.00 (52.5-53.66), MI $32.81(31.43-32.36)$.

\section{Description}

\section{Worker}

With the characters typical of the genus (see diagnosis and description in Brandão et al. 1999 and Borowiec \& Longino 2011) and of the L. biconstricta species-group (see diagnosis of the group above). Other characters or differences are as follows:

HEAD. Elongate and rectangular with lateral margin nearly straight and parallel. Posterior corner rounded. Posterior margin modestly convex, almost straight. Parafrontal ridge absent. Clypeal lamella

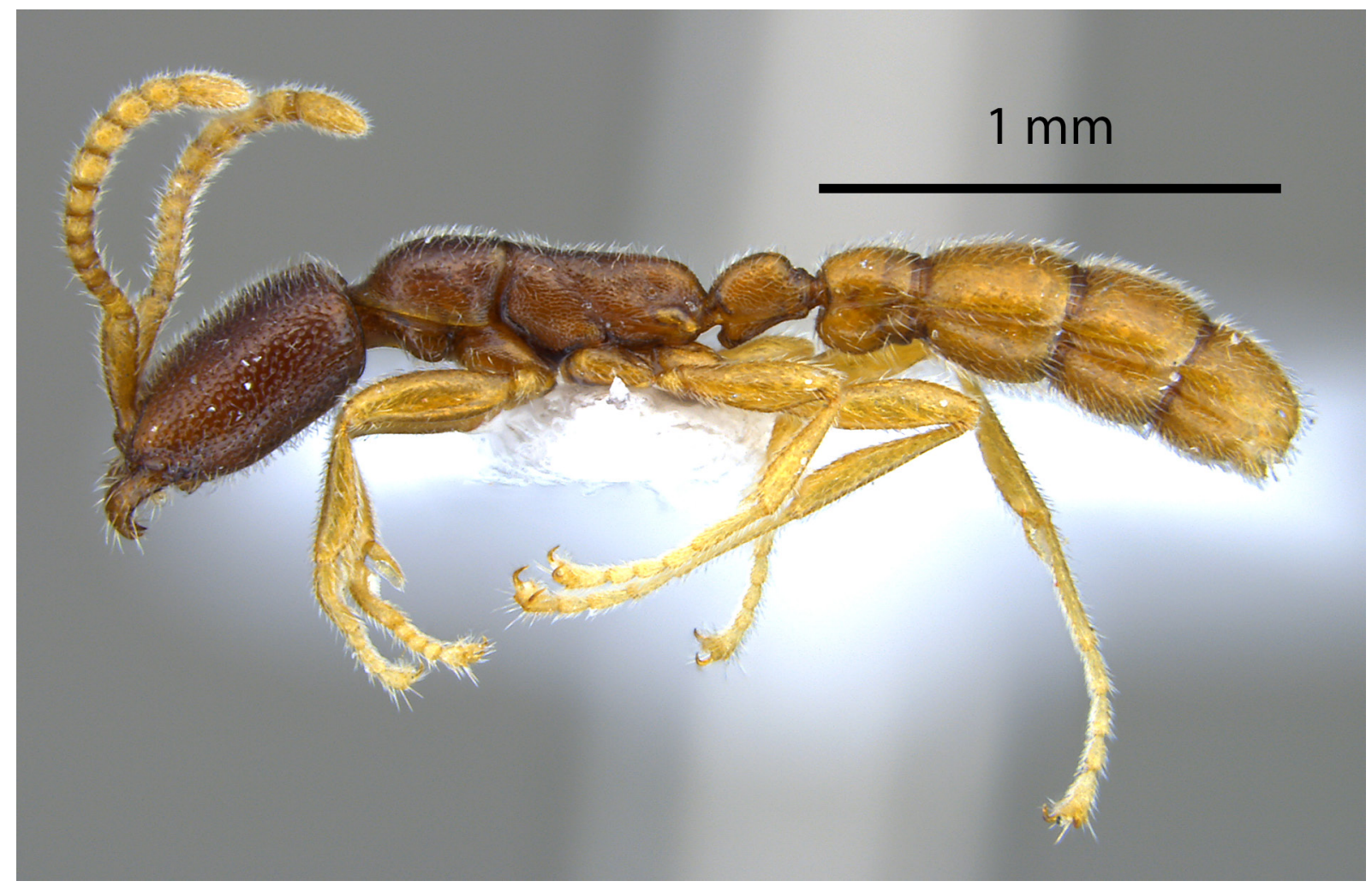

Fig. 5. Habitus in lateral view of paratype (specimen code 4060601) of Leptanilloides prometea Delsinne \& Donoso sp. nov. Note the rounded anterior projection of the subpetiolar process, which differs from the acute shape observed in the specimen on Figs $4 \mathrm{C}$ and $6 \mathrm{E}$. 
strongly convex (Fig. 6C). Masticatory margin of mandible dentate but teeth extremely minute, blunt and irregularly shaped, difficult to discern even under magnifications of about 100× (Fig. 6C). Basal and masticatory margins united by a broad convexity. Basal margin faintly crenulate. Labial palp not readily visible but, at least, one-segmented, maxillary palp two-segmented. Hypostomal anterior border rounded and slightly projected outward but without forming a distinct tooth (Fig. 6A). Scape when laid back reaching about medial distance to posterior margin of head.

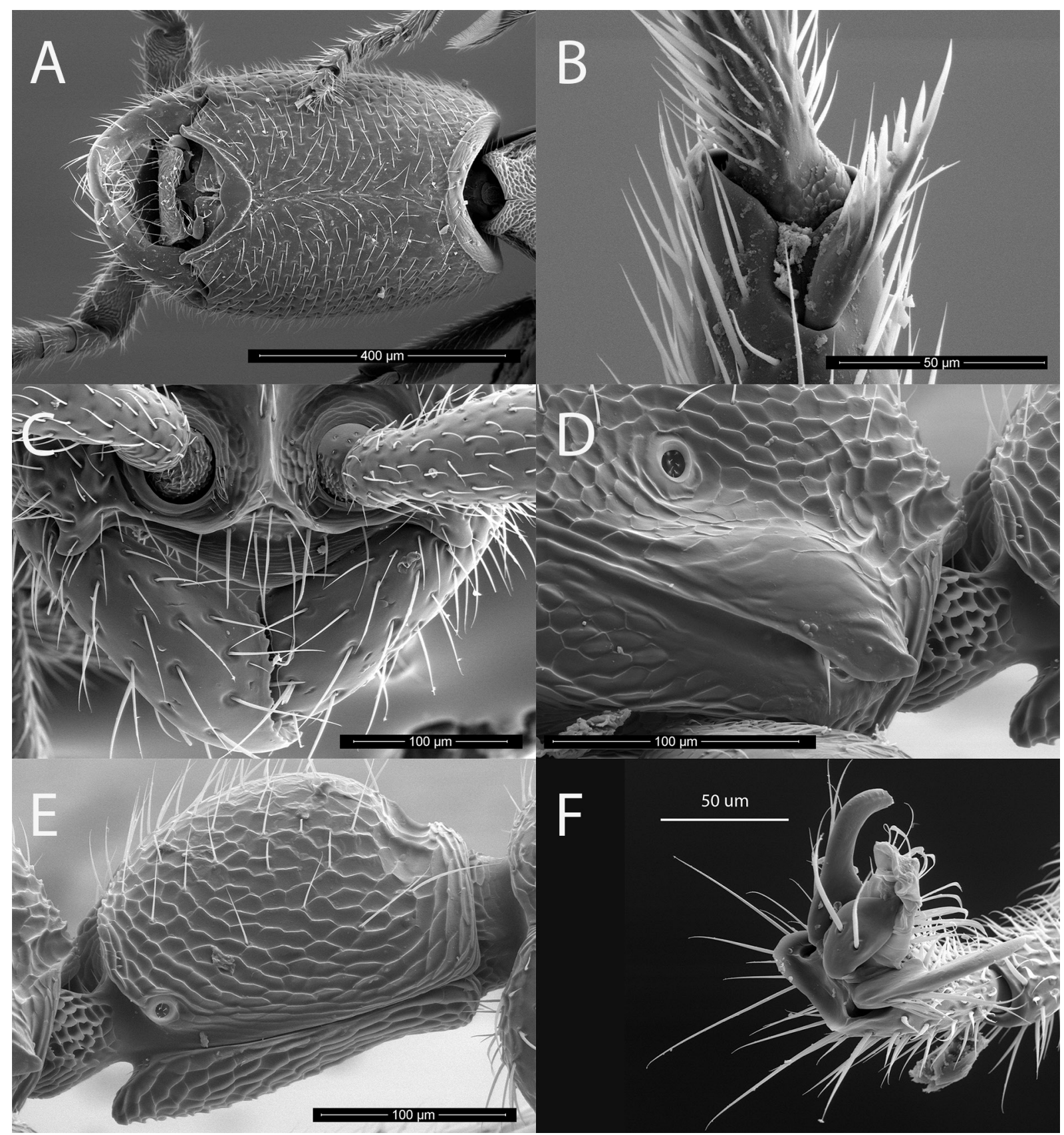

Fig. 6. Leptanilloides prometea Delsinne \& Donoso sp. nov. Paratype worker (specimen code 4052301). A. Head, ventral view. B. Mesotibial pectinate spur. C. Anterior part of the head in full-face view, showing vertical and fused frontal carinae, exposed antennal socket, well-developed lateroclypeal tooth, strongly convex clypeal lamella and subtriangular mandible with minute denticles along its inner margin. D. Lower part of propodeum in lateral view, showing the flange over the metapleural gland opening. E. Petiole in lateral view. F. Simple claw (hindleg). 
Mesosoma. Flange over metapleural gland opening conspicuous and posteriorly forming short, blunt projection, not surpassing propodeum declivity margin (Fig. 6D). Femur not conspicuously enlarged, relatively slender. Midtibia with one short (i.e., half size of foretibia strigil), pectinate spur (Fig. 6B), although pectination may be difficult to observe even at high magnification. Hindtibia with one broadly pectinate spur roughly as long as strigil. Metatibial gland present, visible at high magnification and good lighting as translucent oval area at apex of tibia, behind spur insertion (Fig. 4D). Metatibial gland pore plate observable in SEM (Fig. 7A-C).

Metasoma. Long and relatively slender. In dorsal view, petiole uniformly rectangular, twice as long as wide, as long as abdominal segment III (postpetiole). Anterior face concave, posterior face straight. In lateral view, petiole height approximately $1 / 4$ smaller than height of abdominal segment III. Petiolar tergite dome-shaped, with short and poorly differentiated anterior and posterior faces, maximum height situated in posterior half. Short tubulated portion present posteriorly. Petiolar spiracle inconspicuous, not in excavation, set near anterior rim of tergite, similar in form and slightly smaller in diameter than propodeal spiracle. Subpetiolar process with ventral margin relatively straight (not distinctly bulging), and without posterior angle (Fig. 6E). Anterior projection of subpetiolar process variable in shape, acute to rounded (Figs 5, 6E). Maximum height of petiolar sternite situated in its anterior half. In dorsal view, abdominal segment III (postpetiole) trapezoid, with straight, parallel anterior and posterior faces. Posterior face almost twice as long as anterior face. In lateral view, tergite evenly convex, without well-differentiated posterior face. Sternite evenly rounded, slightly bulging anteriorly. In dorsal view, abdominal segments IV-VI subequal in length.

Pilosity And SCUlpture. Mandible smooth and shiny, with few scattered piligerous punctures. Head with abundant deep piligerous punctures and smooth interspaces on average equaling puncture diameter, except on ventral side and front where punctures are sparser, separated by more than their diameter. Mesosoma and abdomen more finely and sparsely punctate. Fine reticulate sculpture present laterally on lower pronotum, entire mesopleuron, propodeum, and petiole. Body and appendages with abundant, short and subdecumbent to suberect hairs. Body color brownish to reddish, with head and mesosoma tending to be darker than petiole and gaster. Legs and antennae yellowish.

\section{Gyne}

Unknown.

\section{Male}

Unknown.

\section{Distribution}

Only known from the type locality.

\section{Biology}

Unknown. All the specimens were collected from a single reserve bordering the Podocarpus National Park on the eastern Andean slope of southern Ecuador. The habitat is an evergreen lower montane forest (Homeier et al. 2008) which is in nearly pristine condition. The forest harbours more than 300 tree species, with Lauraceae, Melastomataceae and Rubiaceae being the most species-rich families (Homeier et al. 2012). The mean annual temperature is $c .15^{\circ} \mathrm{C}$ and mean annual precipitation is $c .2200 \mathrm{~mm}$, with low seasonality (Bendix et al. 2008). Soils of the sampling area are cambisols, with a very thick (often $>50 \mathrm{~cm}$ ) leaf litter layer (Homeier et al. 2012). Soil texture is sandy silt loam; proportion of sand, silt and clay is $41 \%, 52 \%$, and $6 \%$, respectively; mean $\mathrm{pH}=3.2 \pm 0.1 \mathrm{SD}(\mathrm{n}=24$ soil samples $)$. 


\section{Remarks}

Leptanilloides prometea sp. nov. is the largest species of the L. biconstricta species-group (Fig. 1). The most similar species in habitus and size is L. improvisa, but head of L. prometea sp. nov. is longer (Fig. 1)

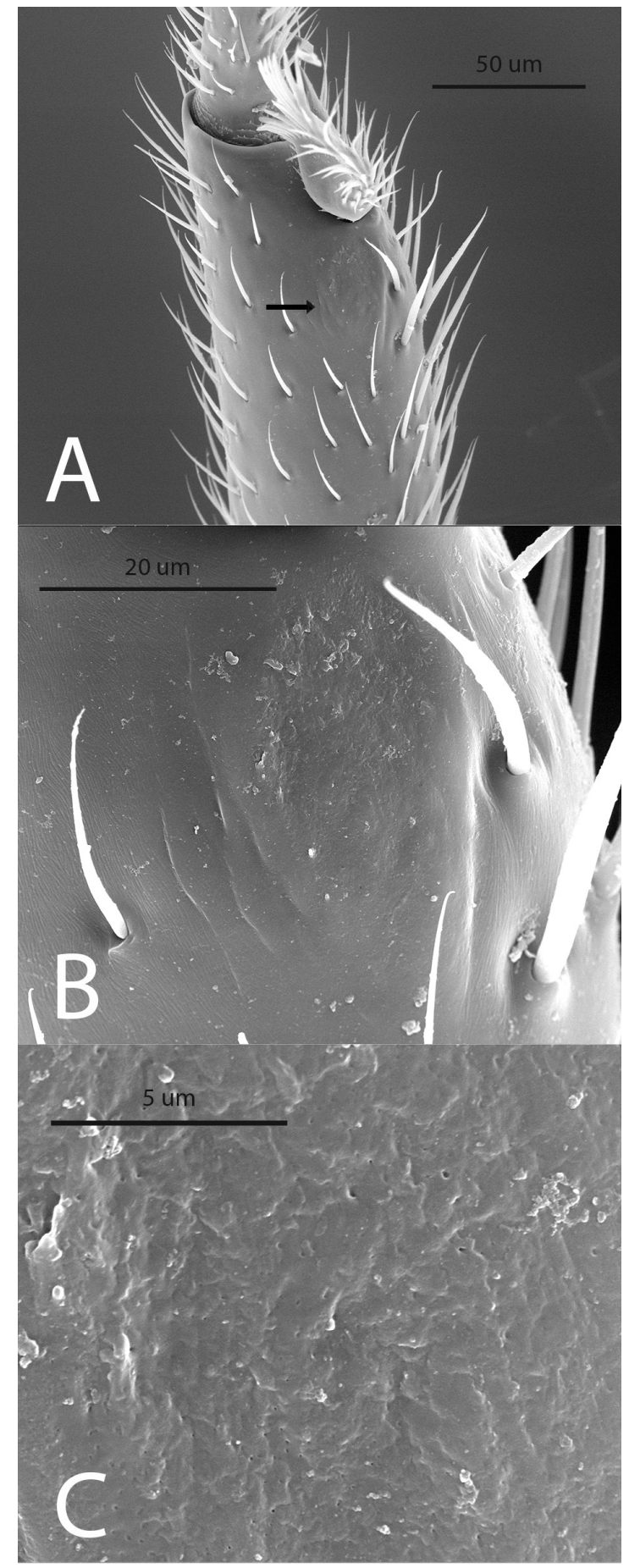

Fig. 7. Leptanilloides prometea Delsinne \& Denoso sp. nov. Scanning electron micrographs of the metatibial apex of paratype worker (specimen code 4052301), showing the metatibial gland pore plate (arrow) at different magnifications.

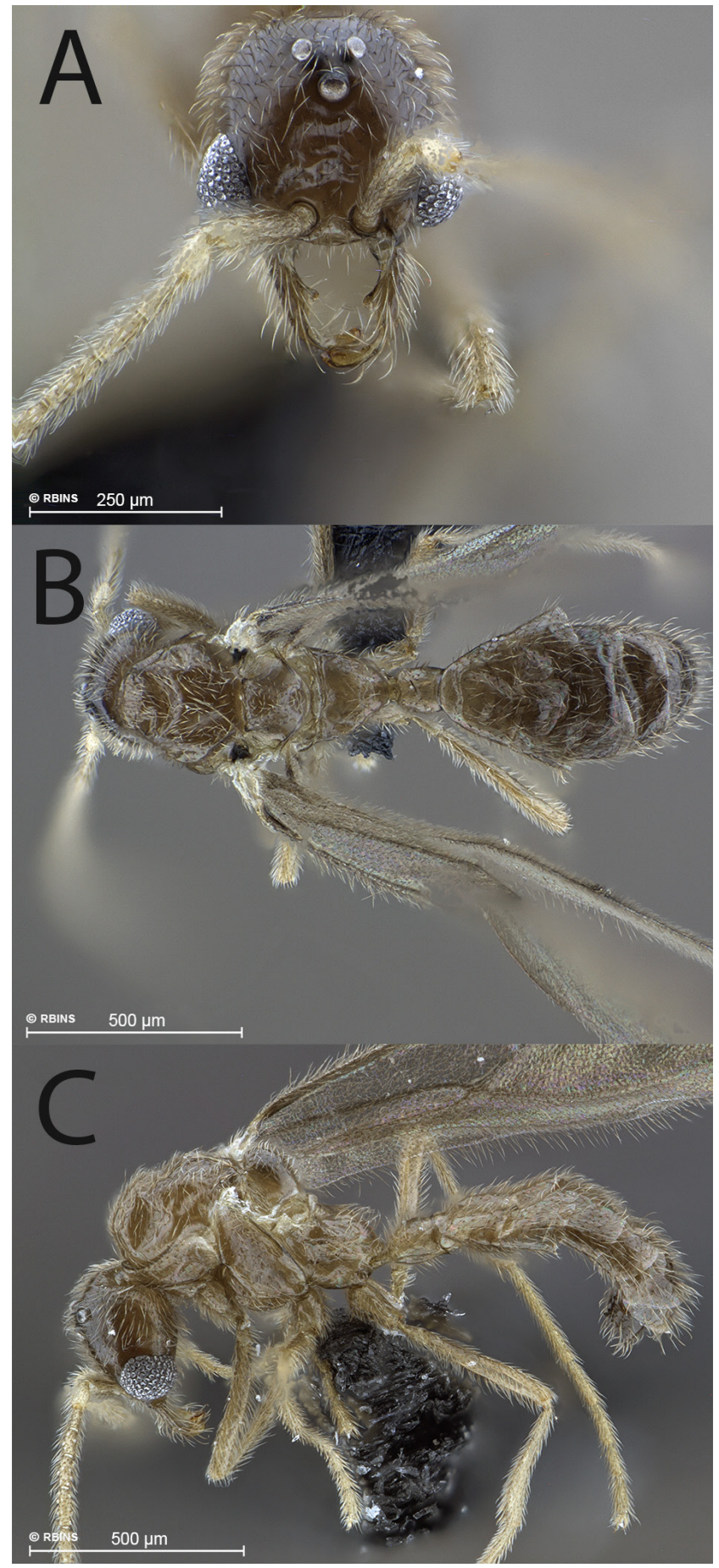

Fig. 8. Leptanilloides 'Male4'(specimencode4870101) from southern Ecuador. A. Head in full face view. B. Habitus in dorsal view. C. Habitus in lateral view. 
and its mandible has only minute and irregular teeth along the masticatory margin (teeth are conspicuous and regularly spaced in L. improvisa). Moreover, $L$. prometea sp. nov. can easily be distinguished from other species in the group by: the presence of a conspicuous lateroclypeal tooth (absent in L. caracola), the evenly rounded sternite of abdominal segment III (bulging anteriorly in L. biconstricta), the petiole being as long as the postpetiole (petiole longer than postpetiole in L. biconstricta), the petiolar sternite being higher in its anterior half (bulging medially in L. gracilis and L. femoralis), the head dorsum with foveolae separated by about their diameter (more densely foveolate in L. sculpturata, with foveolae separated by less than their diameter), and the short, blunt flange over the metapleural gland opening (long and sharply pointed in L. atlantica, L. copalinga and L. erinys).

Leptanilloides sp. 'Male 4' (unassociated to workers)

Figs $8 \mathrm{~A}-\mathrm{C}, 9 \mathrm{~A}-\mathrm{B}, 10 \mathrm{~A}-\mathrm{B}$

\section{Material examined}

ECUADOR: 1 , Zamora-Chinchipe Prov., Reserva Biológica San Francisco, entrance of the T1 trail, 1920 m, 358'44.09" S, 7905'8.26” W, 16-29 Mar. 2011, Malaise trap, coll. Thibaut Delsinne and Tania Milena Arias-Penna (QCAZ, sc 4870101). GenBank accession number: KT601704.

\section{Measurements (in $\mathrm{mm}$ ) and indices}

HW 0.34, HL 0.31, SL 0.24, LAII 0.07, LAIII 0.09, LAIV 0.09, LAXIII 0.17, EL 0.13, MaL 0.16, PrW 0.33, WL 0.66, MH 0.36, PL 0.12, PW 0.11, PPL 0.33, PPW 0.33, AivL 0.13, AivW 0.33, FFeL 0.36, FFeW 0.06, HFeL 0.49, HTL 0.4, CI 110.71, SI 70.97, PI 90.91, MI 54.24.

\section{Description}

HEAD. Broader than long, with large convex eye that occupies anterior half of side of head. Mandible slender, falcate, twisted at apex, overlapping at closure (Fig. 8A). Basal and masticatory margins strongly concave, separated by well-developed tooth. External margin straight along basal and medial lengths but strongly bent at apex. Mandible longer than eye length. Lateroclypeal tooth and hypostomal tooth lacking, clypeus short and transverse, with narrow clypeal lamella (apron). Antennal socket horizontal and exposed, located at anterior clypeal margin, margin not projecting anteriorly beyond ventral articulation with labrum. Antenna 13-segmented, each segment longer than wide, with second segment shortest. Scape of moderate length, 1.5 times longer than length of ultimate antennal segment. Scape length nearly four times length of second antennal segment. Lateral ocellus separated from median ocellus by its diameter. Distance between lateral ocelli similar to distance between median and lateral ocellus; as a result, ocelli forming equilateral triangle.

Mesosoma. Pronotum U-shaped in dorsal view and reduced anteromedially to thin horizontal strip, set below level of dorsally protruding mesonotum and triangular in lateral view, with pointed posterior apex directed towards wing base. Mesoscutum lacking notaulus. Parapsidal line not discerned, apparently absent. Axillae depressed, not meeting medially, connected by narrow furrow; tegula very small and inconspicuous. Mesopleuron lacking oblique transverse sulcus and hence not divided into anepisternum and katepisternum. Transcutal sulcus deeply impressed. Mesoscutum and mesoscutellum prominently bulging, in lateral view. Metapleural gland not discernable. Propodeum rounded in profile, with dorsal and declivous faces only poorly differentiated; dorsal surface somewhat shorter than declivous. Propodeal spiracle small, circular, positioned slightly above midheight of propodeum and slightly posterior to metanotum. Leg slender, mid tibia with one simple and hind tibia with one simple spur (observed under $50 \times$ magnification), pretarsal claw lacking preapical tooth.

Wings (Fig. 9A-B). With relatively well-developed venation (for Leptanilloides). Forewing with C present, tubular and pigmented. $\mathrm{Sc}+\mathrm{R}$ approximated to wing margin, very narrow. $\mathrm{Sc}+\mathrm{R} 1$ in line with 


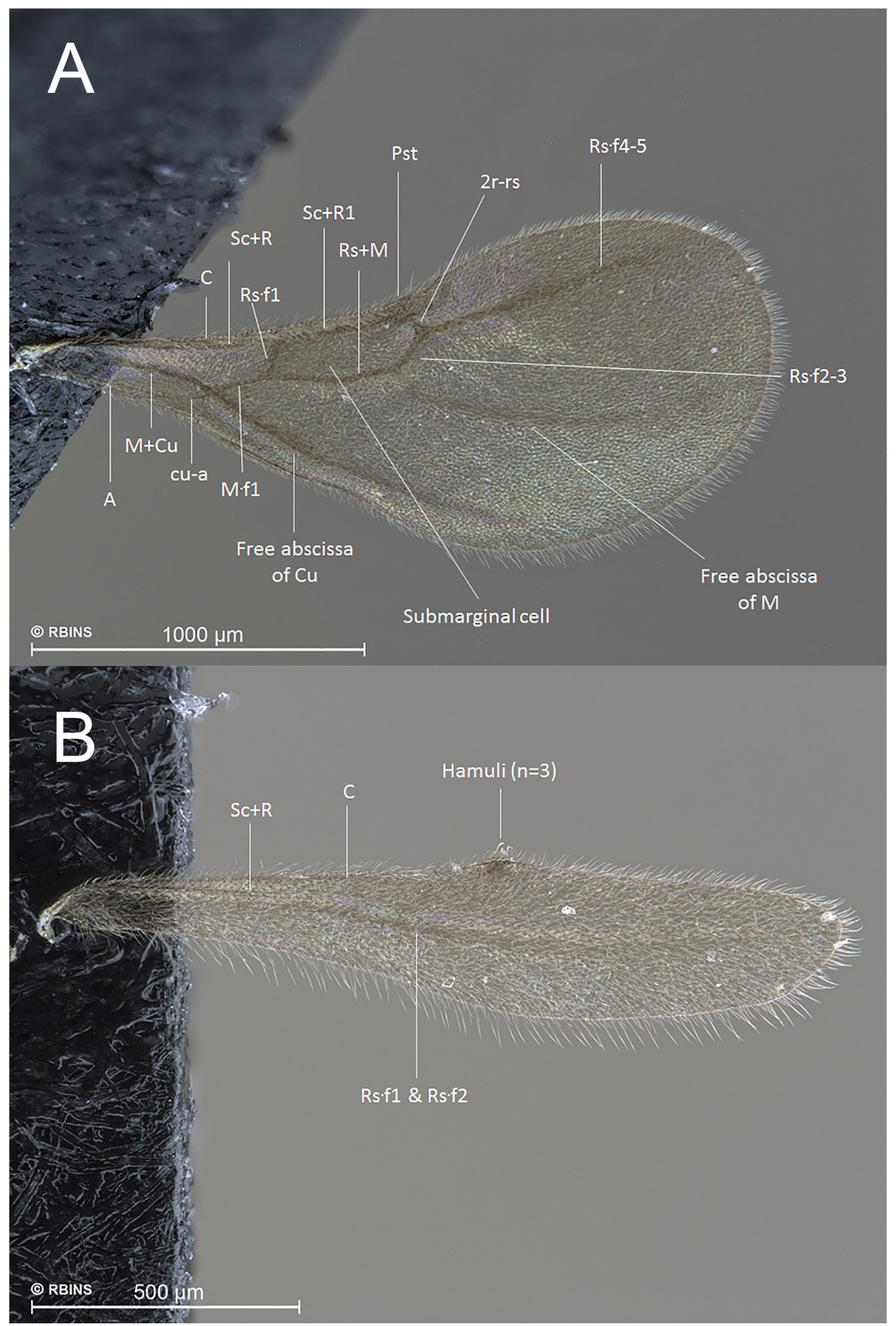

Fig. 9. Wings of Leptanilloides 'Male 4' (specimen code 4870101) and terminology used in the description. A. Forewing. B. Hindwing. Abbreviations: 2r-rs $=$ second radial-radial sector crossvein, $\mathrm{A}=$ anal vein, $\mathrm{C}=$ costal vein, $\mathrm{Cu}=$ cubital vein, $\mathrm{cu}-\mathrm{a}=$ cubital-anal crossvein, $\mathrm{M}=$ medial vein, $\mathrm{M} \cdot \mathrm{fl}=$ first free abscissa of medial vein, $\mathrm{M}+\mathrm{Cu}=$ fused medial-cubital veins, $\mathrm{Pst}=$ pterostigma, $\mathrm{Rs}+\mathrm{M}=$ fused medial and radial sector veins, $\mathrm{Rs}=$ radial sector, Rs·f1 (to Rs·f5) $=$ first (to fifth) free abscissa of radial sector vein, $\mathrm{Sc}+\mathrm{R}=$ fused subcostal and radial veins, $\mathrm{Sc}+\mathrm{R} 1$ : fused subcostal and first radial veins. 
$\mathrm{Sc}+\mathrm{R}$, tubular. Pterostigma well-marked. $\mathrm{M}+\mathrm{Cu}$ tubular and pigmented, curved towards posterior wing margin before division. Rs·fl nebulous. $\mathrm{M} \cdot \mathrm{fl}$ pigmented, tubular. Rs $+\mathrm{M}, \mathrm{Rs} \cdot \mathrm{f} 2$, and Rs $\mathrm{f} 3$ all joined, tubular and pigmented. 1r-rs absent. 2r-rs present, tubular and pigmented. Rs·f4 and Rs·f5 joined and not differentiated in absence of $2 \mathrm{rs}-\mathrm{m}$. Rs $\mathrm{f} 4 \& \mathrm{Rs} \cdot \mathrm{f5}$ partly tubular, then nebulous, terminating before wing margin. $\mathrm{M}$ and $\mathrm{Cu}$ diverging at cu-a. Free abscissa of $\mathrm{M}$ partly nebulous, then spectral, very weakly visible, joining to Rs $+M \& R s \cdot f 2 \& R s \cdot f 3$. Abscissa of $\mathrm{Cu}$ joined, nebulous throughout most of length and continuing as spectral. Vein A tubular, joining cu-a at obtuse angle and confluent with Rs $+M$, apparently absent beyond cu-a. Posterior margin of fore wing with fold where hamuli attach, narrow, conspicuous. Hindwing with $\mathrm{C}$ present, narrow and faint. Anterior hindwing margin with small differentiated pigmentation area located in distal half of wing. Three hamuli originate in pigmented region. $\mathrm{Sc}+\mathrm{R}$ present, nebulous, almost reaching third of wing length. Sc+R1 absent. Rs $\cdot f 1 \& R s \cdot f 2$ partly nebulous, then spectral. Jugal lobe absent.

Metasoma. Slender in lateral view, obovate in dorsal view, widest at abdominal segment V. Petiole (abdominal segment II) longer than high or wide, rectangular in dorsal view, with convex lateral margin, ovate in lateral view, and weakly constricted posteriorly, helcium thus apparently quite broad. Petiolar spiracle located on anterior third of segment, near anterodorsal extremity. Abdominal segment III three times larger than petiole at its maximum width, not developed as postpetiole nor separated from abdominal segment IV by marked constriction. Abdominal spiracle III located on anterior third of tergite. Abdominal segments II and III with tergosternal fusion. Abdominal segment IV and succeeding segments lacking tergosternal fusion. Spiracle present on anterior third of tergite IV. Abdominal segments V and VI not separated from succeeding segments by constrictions. Abdominal spiracles $\mathrm{V}$ and VI indiscernible. Abdominal tergite VIII (pygidium) small and simple but visible dorsally, not wholly covered by abdominal tergite VII.

Genitalia (Fig. 10A-B). Pygostyle absent. Abdominal sternite IX (subgenital plate) with posterior margin broadly and deeply concave but not bifurcate. Basal ring present, not hypertrophied. Paramere relatively small, harpago rounded at apex; paramere shorter than petiole length. Volsella a simple, broad lobe, lacking differentiated cuspis. Aedeagus subequal in length to paramere and volsella, simple, narrow, distally spatulate.

Pilosity AND SCUlPtURE. Integument mostly smooth and shiny, with scattered piligerous punctures. Pilosity common on most of body, suberect to decumbent. Color light brown, head and metasoma past abdominal segment III slightly darker. Appendages (antennae, mandibles, legs) lighter than body.

\section{Distribution}

Only known from the sampling locality.

\section{Remarks}

The male (specimen code 4870101) collected in southern Ecuador is easily distinguished from any other leptanilloid males (either of Leptanilloides or Amyrmex species, males of all species of Asphinctanilloides being unknown) by the unique shape of its mandible. We did not give it a specific name because it is not associated with workers. However, we called it 'Male 4' to indicate that it is different from the three males ('Male 1' to 'Male 3') described in Borowiec \& Longino (2011), which are also without specific names.

The wing venation of 'Male 4' is relatively similar to that of 'Male 3' in Borowiec \& Longino (2011), except that the free abscissa of $M$ on the forewing joins Rs $+M \& R s \cdot f 2 \& R s \cdot f 3$ (not joining in 'Male 3') and $\mathrm{Sc}+\mathrm{R} 1$ is not visible on the hindwing (present as a short nebulous stub in 'Male 3'). 'Males 1 and 2' of Borowiec \& Longino (2011) have more reduced venation, as do the males of Amyrmex (Ward \& 


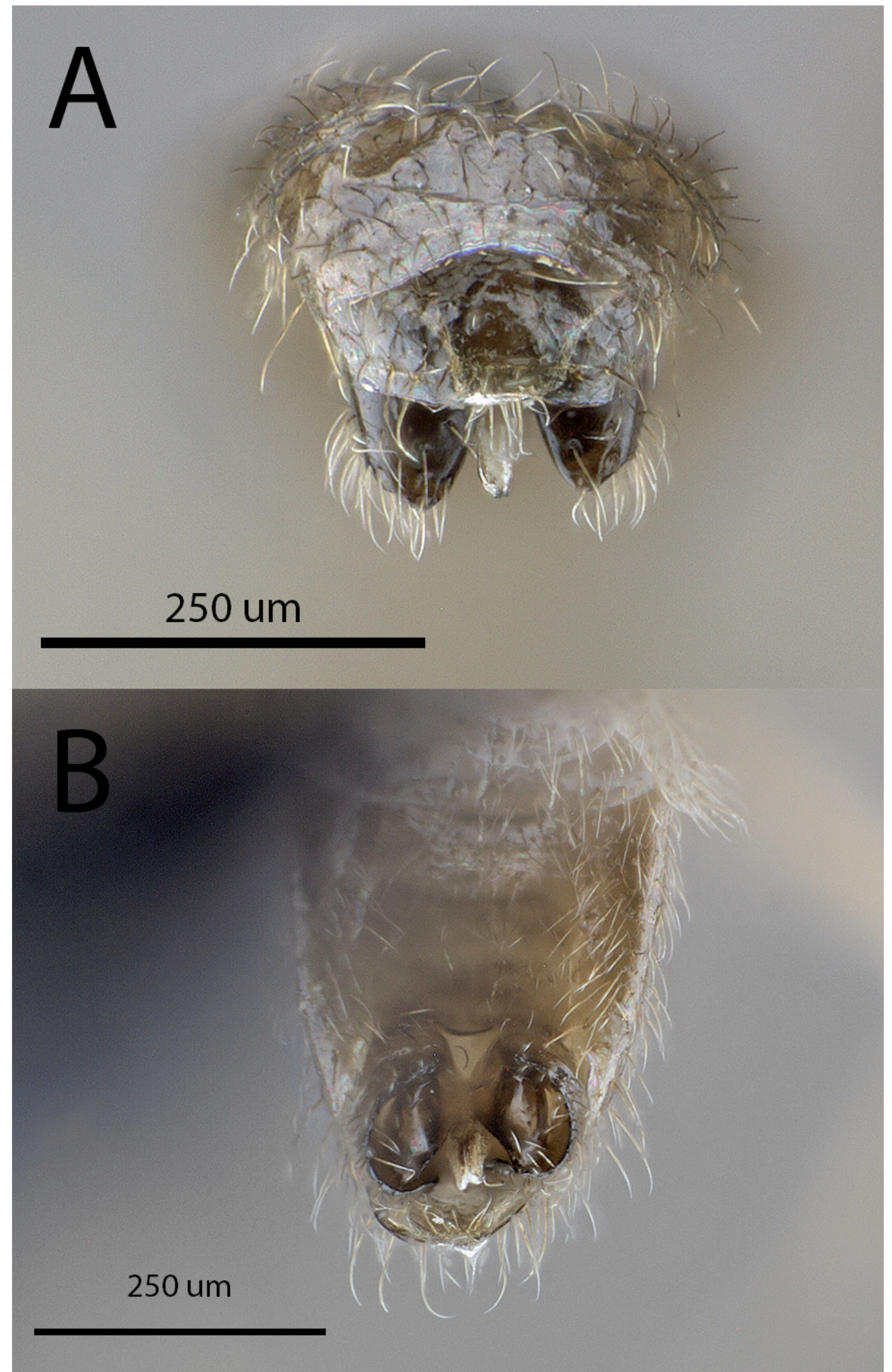

Fig. 10. Genitalia of Leptanilloides 'Male 4' (specimen code 4870101). A. In posterior view. B. In ventral view. 
Brady 2009). The forewing venation of $L$. mckennae and $L$. nubecula is also closely similar but, in these species, veins $\mathrm{M}$ and $\mathrm{Cu}$ diverge distal to crossvein cu-a (diverging at cu-a in 'Male 4'). Table 1 lists informative characters to separate leptanilloid males.

\section{DNA results}

The COI sequences of the two new species and 'Male 4' differ significantly from each other (p-distances ranging from 18.8 to $21.7 \%$ ) (Fig. 11). They also diverge (18-21.8\%) from the other Leptanilloides DNA barcodes available in BOLD (6 specimens, 2 species: L. gracilis from the L. biconstricta speciesgroup and L. nubecula from the L. legionaria species-group).

Our phylogenetic analyses constructed on the basis of the nuclear gene Wg support one clade consisting of L. prometea sp. nov., L. femoralis, L. gracilis and Amyrmex sp. and another clade composed of L. nubecula, L. nomada and L. mckennae. Both clades are supported by bootstrap values of $98 \%$ and $99 \%$ in the neighbour-joining tree, $97 \%$ and $100 \%$ in the most parsimonious tree, $83 \%$ and $100 \%$ in the tree with maximum likelihood and by posterior probabilities of 1 in the tree built with Bayesian inference (Fig. 12).

\section{Discussion}

The discovery of two new Leptanilloides species and a distinct male, which potentially belongs to another species, confirms assertions such as "there are many more species to be found and we have no idea how species-rich the [leptanilloid clade] may be" (Longino 2003), "new species [of Leptanilloides] will continue to be discovered" (Borowiec \& Longino 2011), and "the ants may be much more common and widespread than presently known" (Silva et al. 2013). The rate of species discovery within the leptanilloid clade is indeed rapidly increasing (Fig. 13), and should continue to do so, thanks to growing interest in the subterranean ant assemblages, considered as the "final frontier" in the study of the biodiversity of Formicidae (Ryder Wilkie et al. 2007) and linked with the development of new

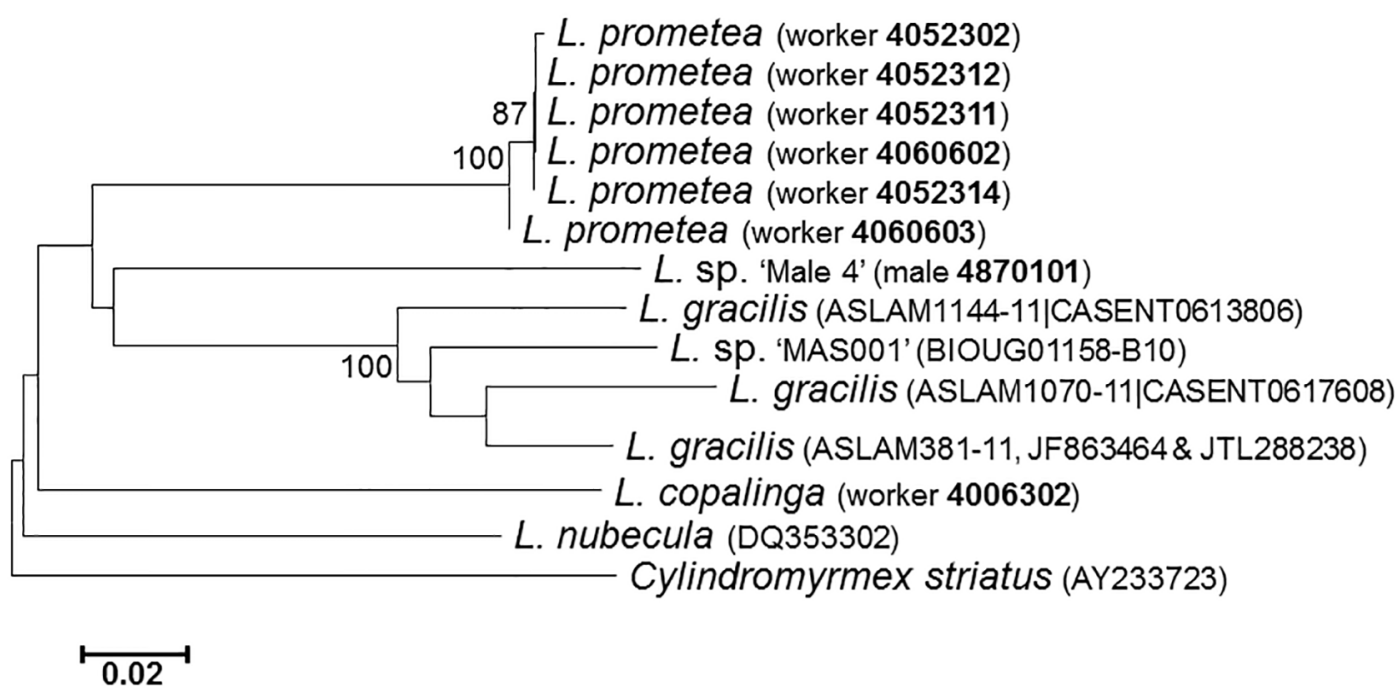

Fig. 11. Neighbour-joining tree showing p-distances among DNA sequences of the mitochondrial COI barcode fragment obtained for all specimens of Leptanilloides Mann, 1823 sequenced here and available in GenBank and BOLD. The tree was rooted with a COI sequence of Cylindromyrmex striatus Mayr, 1870 (GenBank accession number AY233723). Labels provide species identifications and field IDs (in bold) or GenBank or BOLD numbers. Values at nodes indicate bootstrap support only if it was above $80 \%$. 


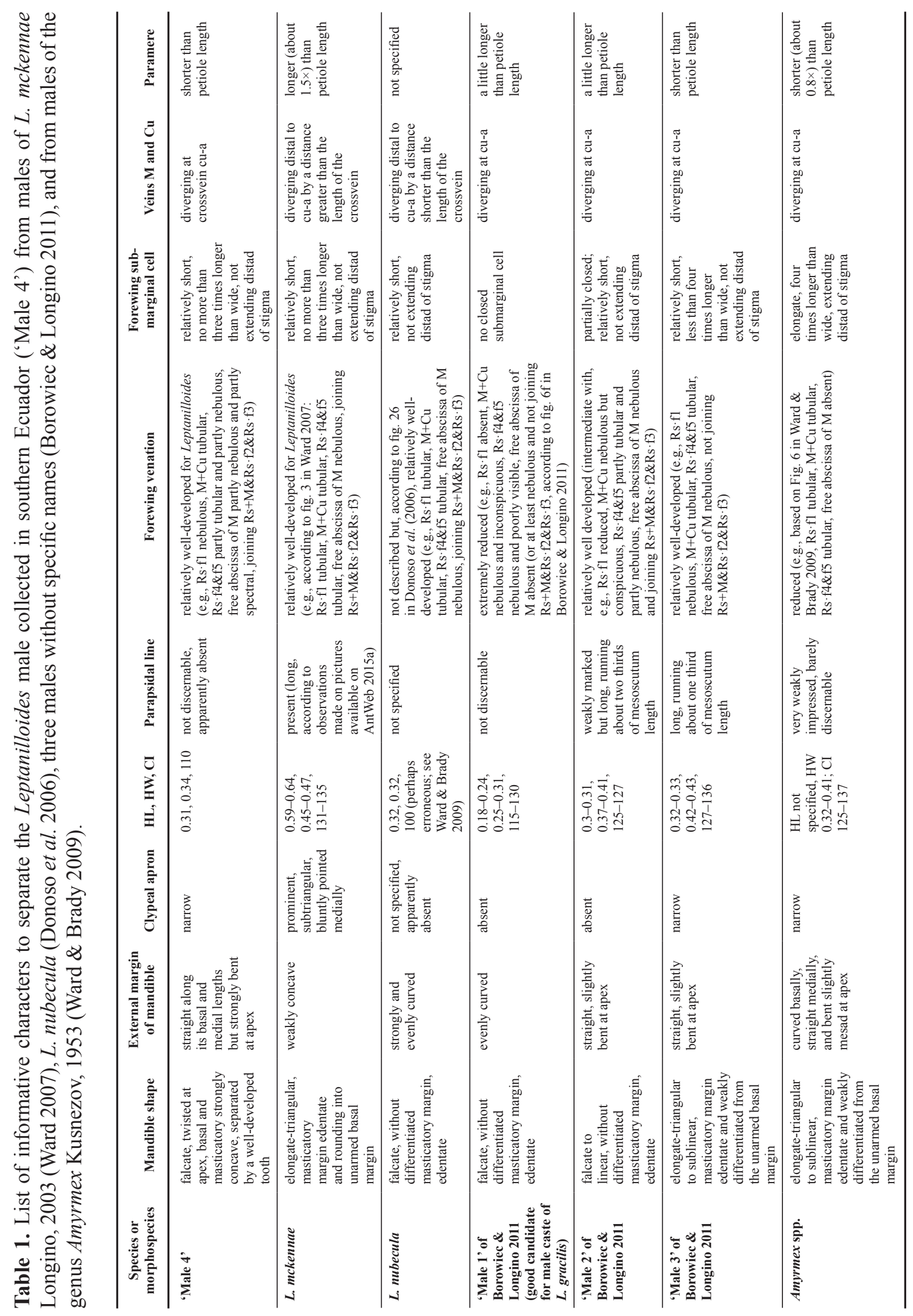


techniques designed to specifically collect this subterranean ant fauna (Weissflog et al. 2000; Berghoff et al. 2003; Ryder Wilkie et al. 2007; Brandão et al. 2008; Schmidt \& Solar 2010).

Workers of L. copalinga sp. nov. and L. prometea sp. nov. presented the characteristic morphology of species from the L. biconstricta species-group. Interestingly, our phylogenetic analyses, albeit based on a single nuclear gene, supported the existence of the L. biconstricta and L. legionaria species-groups, and placed L. prometea sp. nov. within the clade composed of the L. biconstricta species-group, supporting the morphology-based hypothesis. Our results also suggest that COI can be used as a molecular tool to identify species of Leptanilloides, since large divergences were observed at COI among specimens that were assigned to different species on the basis of morphology. Unfortunately, these taxa are currently known from a limited number of workers and are not all represented in the library of DNA barcodes. Therefore, we could not compare the new sequences with those of all other species in the genus. It remains necessary to accumulate information concerning the leptanilloid clade to facilitate male-worker caste association and to establish generic limits with confidence. This case study highlights the interest in building a comprehensive reference library of COI barcodes and other DNA markers.

The characters of the L. legionaria species-group are reminiscent of the three currently known species of Asphinctanilloides (Longino 2003; Donoso et al. 2006; Borowiec \& Longino 2011) [two workers of a fourth species were recently discovered but have not yet been formally described (Silvestre et al. 2012; Silvestre pers. comm.)]. However, Asphinctanilloides does not exhibit constrictions (cincti) between the gastral segments, a condition considered as plesiomorphic within the leptanilloid clade (Brandão et al. 1999). In addition, four sting characters were identified as apomorphies for Asphinctanilloides, but because the sting apparatus of only one species of the L. legionaria species-group has been studied so far (L. legionaria in Brandão et al. 1999), it is not possible to assert that these traits are absent in all species of Leptanilloides.

The monotypic Amyrmex is only known from its male (Ward \& Brady 2009). The genus was initially placed in Dolichoderinae Forel, 1878, but genetic studies, based on fragments of 7-11 nuclear genes, confirmed that it is nested within Leptanilloides, apparently as sister of the L. biconstricta species-group

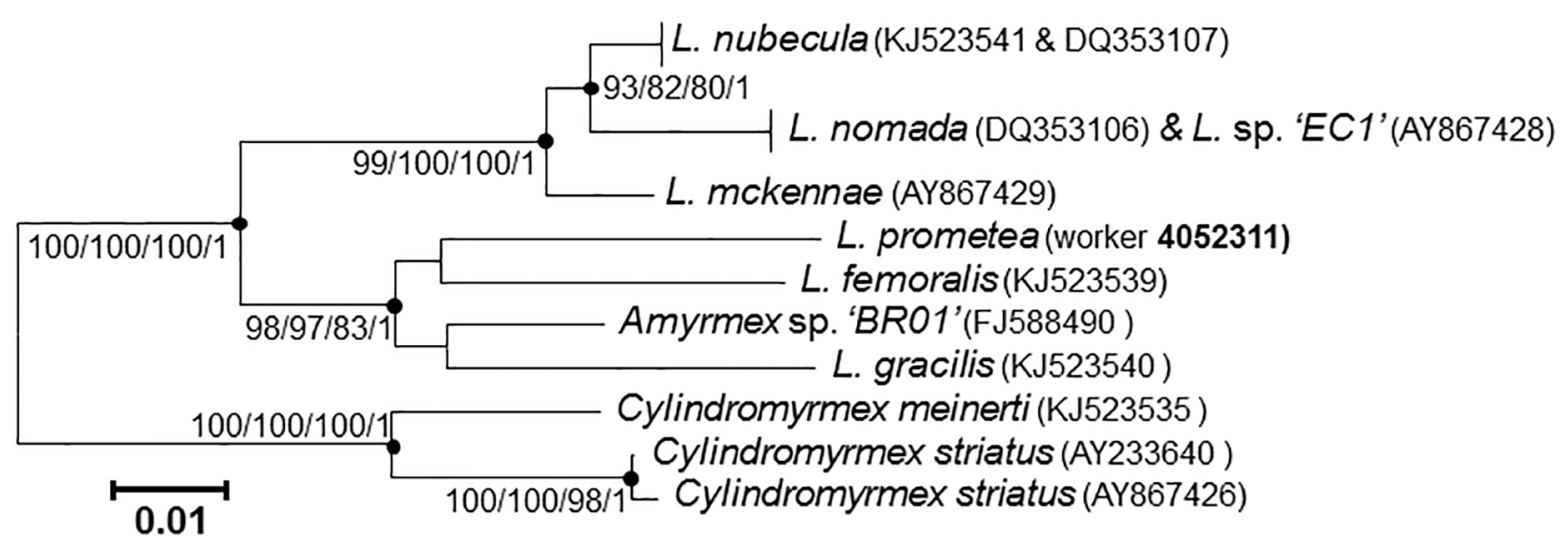

Fig. 12. Neighbour-joining tree showing p-distances among DNA sequences of the wingless nuclear marker obtained for specimens of Leptanilloides Mann, 1823, Amyrmex Kusnezov, 1953 and Cylindromyrmex Mayr, 1870 (as outgroup), available in GenBank and sequenced here (specimen code 4052311). Labels provide species identifications and field IDs (in bold) or GenBank or BOLD numbers. Values at nodes correspond to the bootstrap values (\%) and posterior probabilities obtained in the Neighbourjoining/parsimony/maximum likelihood/Bayesian inference analyses. Bootstrap values $<80 \%$ and posterior probabilities $<0.95$ are not indicated. 
(Ward \& Brady 2009; Brady et al. 2014) or even nested within this species-group (this study). It is therefore clear that generic limits within the leptanilloid clade should be reassessed (Longino 2003; Ward \& Brady 2009; Borowiec \& Longino 2011). However, a broad set of uncertainties hampers that task, including (1) the unknown molecular-based phylogenetic position of Asphinctanilloides, (2) the unknown worker and male caste of Amyrmex and Asphinctanilloides, respectively, (3) the poor morphological distinction between the L. legionaria species-group and Asphinctanilloides, (4) the lack of collection series for nearly all species to correctly appreciate intra- and interspecific morphological variations, and (5) the availability of molecular data for only a limited number of species of Leptanilloides.

The morphology of the two new species of Leptanilloides corresponds to the diagnosis of the genus based on the worker caste offered by Borowiec \& Longino (2011), except that these species have one pectinate spur on both mid- and hindtibiae, giving the spur formula $1 \mathrm{p}, 1 \mathrm{p}$. The midtibial spur is small, making the pectination difficult to observe with a stereo microscope even at high magnification; however, SEM examinations were conclusive. Hitherto, the spur formula in species of Leptanilloides has been considered to be either $1 \mathrm{~s}, 1 \mathrm{p}$ or $2 \mathrm{~s}, 2 \mathrm{~s}$ (Borowiec \& Longino 2011). We had the opportunity to study paratypes of L. nomada (QCAZ I 119692) and L. nubecula (QCAZ I 119693, QCAZ I 119694). The three specimens possess a single short, but pectinate midtibial spur. This character also seems to be present in L. atlantica (Silva et al. 2013: fig. 2d). It could be interesting to reassess this criterion in previously described species of Leptanilloides and Asphinctanilloides, in order to evaluate its taxonomic value.

A metatibial gland was detected in L. prometea sp. nov. (Fig. 7). In stereo microscopy, the gland reservoir is visible under the translucent cuticle at the base of the hindtibial spur, but observing it requires good

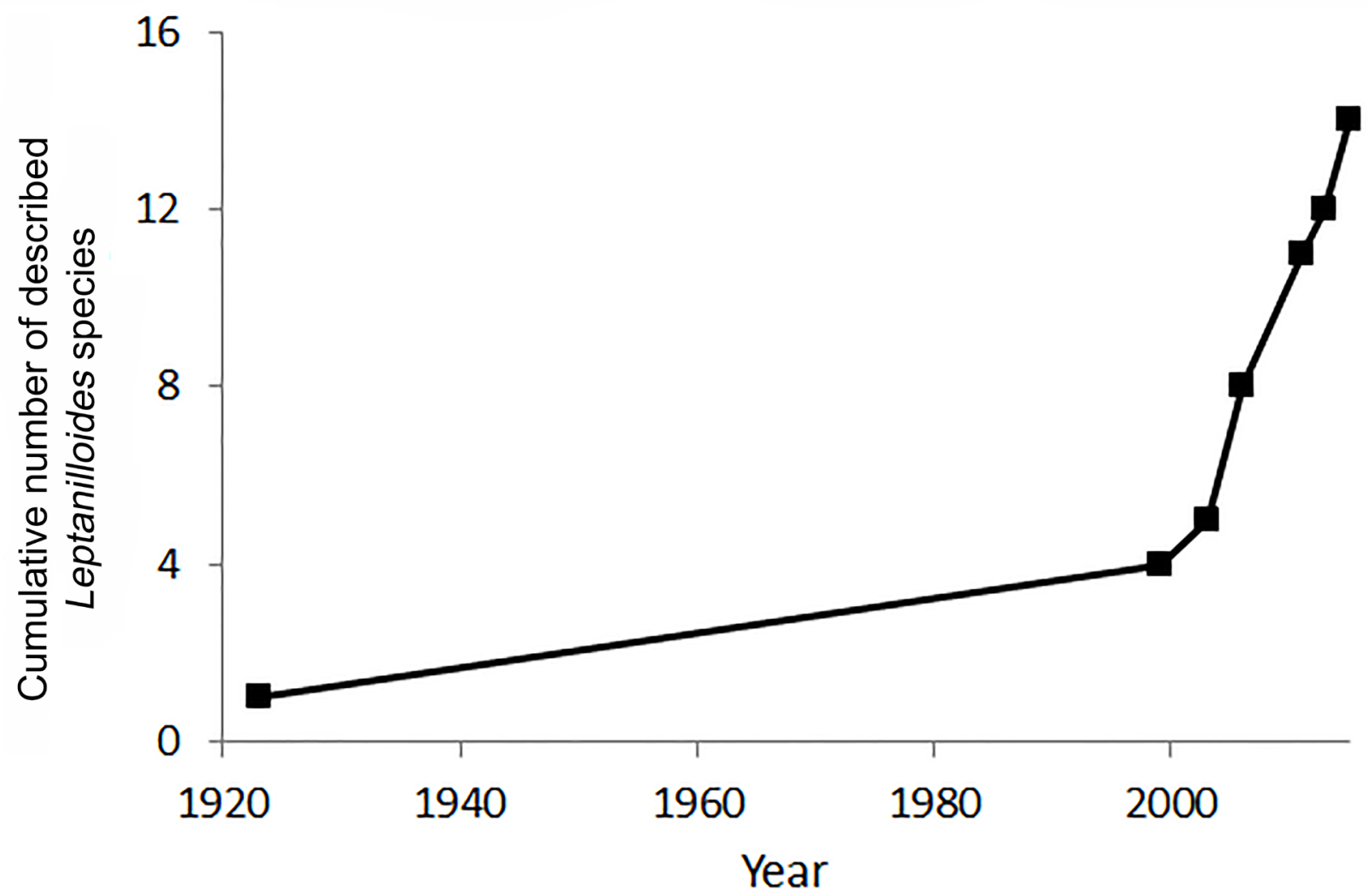

Fig. 13. Cumulative number of described species of Leptanilloides Mann, 1823 over time, since the description of L. biconstricta Mann, 1823. 
lighting. In SEM, the gland area appears as an irregular patch of porous cuticle, contrasting with the smoother surrounding surface, as in L. erinys of the L. biconstricta species-group and L. nubecula of the L. legionaria species-group (Borowiec \& Longino 2011). We were not able, however, to discern a metatibial gland in L. copalinga sp. nov.

As already noted by Donoso et al. (2006), the mandibles of Leptanilloides males vary greatly in shape, ranging from elongate-triangular to falcate (sickle-shaped), and with basal and masticatory margins ranging from undifferentiated to forming two distinct concavities. In Eciton Latreille, 1804 and Dorylus Fabricius, 1793, two other genera of Dorylinae, males use their sickle-shaped mandibles to grab the dichthadiigyne at her petiolar horns during copulation (Kronauer \& Boomsma 2007). In Leptanilloides, the gyne caste is known for only two species, L. nubecula (Donoso et al. 2006) and L. erinys (Borowiec \& Longino 2011). In both species, the gyne is subdichthadiiform with an enlarged petiole but without the dorsal or lateral horns typical of Eciton and Dorylus gynes. It is reasonable to expect that most males of Leptanilloides also use their elongate mandibles to grab the female behind the petiole during copulation. However, the variety of mandibular shapes also suggests that males may display different reproductive behaviors (Shik et al. 2013).

The recent discovery of $L$. atlantica in the Brazilian Atlantic Forest considerably expanded the geographic range of the genus (Silva et al. 2013). Nevertheless, it seems that the highest diversity of Leptanilloides occurs in the Andes, especially at high elevations. In this respect, the montane forests and páramos of Ecuador are noteworthy, since half of the currently known species of Leptanilloides (i.e., 7 out of 14) were collected in these habitats. Unfortunately, Andean ecosystems are currently being destroyed at an alarming rate (Goerner et al. 2007; Tejedor Garavito et al. 2012; Thies et al. 2014; Curatola Fernández et al. 2015). To determine whether the observed distribution of species of Leptanilloides is a mere sampling artifact or an actually existing pattern (Silva et al. 2013), it would be necessary to (1) carry out more inventories of the subterranean ant fauna in the Andes and elsewhere, and (2) secure the conservation of Andean habitats.

\section{Note added in press}

During the editing process, a $15^{\text {th }}$ species of Leptanilloides, namely L. chihuahuaensis MacGown, Schiefer \& Branstetter, 2015, was described based on six males from western Texas, USA. This species extends the range of the genus $2500 \mathrm{~km}$ to the north and indicates that it possesses a larger ecological niche than suspected, since it can also be found in xeric ecosystems. The COI sequence of $L$. chihuahuaensis is distant by more than $10 \%$ from $L$. copalinga sp. nov., L. prometea sp. nov. and 'Male 4', providing convincing support that $L$. chihuahuaensis is neither the male of $L$. copalinga or L. prometea, nor the same species as 'Male 4'. Moreover, the mandible shape of 'Male 4' remains unique within the genus.

MacGown J.A., Schiefer T.L. \& Branstetter M.G. 2015. First record of the genus Leptanilloides (Hymenoptera: Formicidae: Dorylinae) from the United States. Zootaxa 4006: 392-400. http://dx.doi.org/10.11646/ zootaxa.4006.2.10

\section{Acknowledgements}

We warmly thank Catherine Vits and Boudewijn de Roover from the Copalinga Private Reserve for access to their estate; Jörg Bendix, Felix Matt, Jörg Zeilinger, the DFG-Deutsche Forschungsgemeinschaft Research Unit 816, the team of the Estación Científica San Francisco (ECSF) and Naturaleza y Cultura Internacional for allowing and extensively facilitating our work at ECSF and RBSF; the Ministerio del Ambiente of the Republic of Ecuador for collection permits; Isabelle Bachy, Julien Cillis, Yves Laurent, and Maurice Leponce from RBINS for their help with ant digitization; and Tania Milena Arias-Penna, Delia Magaly Montalván Carrión, and Jaime Peña for assistance during fieldwork. The 
authors thank Marek Borowiec and one anonymous reviewer for insightful comments and suggestions. The fieldwork of this research was funded by the Belgian Federal Science Policy Office (BELSPO) through an Action 1 Impulse for Research, and the molecular analyses by the JEMU-Joint Experimental Molecular Unit. Thibaut Delsinne thanks the Secretary of Higher Education, Science, Technology and Innovation (SENESCYT) of the Government of Ecuador for financial support (Prometeo grant) during the taxonomic study and the writing of this article.

\section{References}

Abouheif E. \& Wray G.A. 2002. Evolution of the gene network underlying wing polyphenism in ants. Science 297: 249-252. http://dx.doi.org/10.1126/science.1071468

AntWeb. 2015a. Species: Leptanilloides mckennae Longino, 2003; list. Available from http://www. antweb.org//browse.do?subfamily=dorylinae $\&$ genus $=$ leptanilloides $\&$ species $=$ mckennae $\&$ rank $=$ specie s\&project=worldants [accessed 18 May 2015]

AntWeb. 2015b. Species: Leptanilloides biconstricta Mann, 1923; list. Available from http://www. antweb.org/browse.do?genus $=$ leptanilloides \&species=biconstricta\&rank=species\&project=worldants [accessed 18 May 2015]

Bendix J., Rollenbeck R., Richter M., Fabian P. \& Emck P. 2008. Climate. In: Beck E., Bendix J., Kottke I., Makeschin F. \& Mosandl R. (eds) Gradients in a Tropical Mountain Ecosystem of Ecuador: 63-73. Ecological Studies 198, Springer, Berlin. http://dx.doi.org/10.1007/978-3-540-73526-7

Berghoff S.M., Maschwitz U. \& Linsenmair K.E. 2003. Hypogaeic and epigaeic ant diversity on Borneo: evaluation of baited sieve buckets as a study method. Tropical Zoology 16: 153-163. http://dx.doi.org/1 $\underline{0.1080 / 03946975.2003 .10531192}$

Bolton B. 1990. Army ants reassessed: the phylogeny and classification of the doryline section (Hymenoptera, Formicidae). Journal of Natural History 24: 1339-1364. http://dx.doi. org/10.1080/00222939000770811

Bolton B. 2003. Synopsis and Classification of Formicidae. Memoirs of the American Entomological Institute 71, American Entomological Institute, Gainesville, FL.

Borowiec M.L. \& Longino J.T. 2011. Three new species and reassessment of the rare Neotropical ant genus Leptanilloides (Hymenoptera, Formicidae, Leptanilloidinae). ZooKeys 133: 19-48. http://dx.doi. org/10.3897/zookeys. 133.1479

Boudinot B. 2015. Contributions to the knowledge of Formicidae (Hymenoptera, Aculeata): a new diagnosis of the family, the first global male-based key to subfamilies, and a treatment of early branching lineages. European Journal of Taxonomy 120: 1-62. http://dx.doi.org/10.5852/ejt.2015.120

Brady S.G. \& Ward P.S. 2005. Morphological phylogeny of army ants and other dorylomorphs (Hymenoptera: Formicidae). Systematic Entomology 30: 593-618. http://dx.doi.org/10.1111/j.1365$\underline{3113.2005 .00290 . \mathrm{x}}$

Brady S.G., Schultz T.R., Fisher B.L. \& Ward P.S. 2014. The rise of army ants and their relatives: diversification of specialized predatory doryline ants. BMC Evolutionary Biology 14: e93. http://dx.doi. org/10.1186/1471-2148-14-93

Brandão C.R.F., Diniz J.L.M., Agosti D. \& Delabie J.H.C. 1999. Revision of the Neotropical ant subfamily Leptanilloidinae. Systematic Entomology 24: 17-36. http://dx.doi.org/10.1046/j.1365$\underline{3113.1999 .00064 . x}$

Brandão C.R.F., Feitosa R.M., Schmidt F.A. \& Ribeiro de Castro Solar R. 2008. Rediscovery of the putatively extinct ant species Simopelta minima (Brandão) (Hymenoptera, Formicidae), with a discussion 
on rarity and conservation status of ant species. Revista Brasileira de Entomologia 52: 480-483. http:// dx.doi.org/10.1590/S0085-56262008000300026

Curatola Fernández G.F., Obermeier W.A., Gerique A., López Sandoval M.F., Lehnert L.W., Thies B. \& Bendix J. 2015. Land cover change in the Andes of Southern Ecuador-Patterns and drivers. Remote Sensing 7: 2509-2542. http://dx.doi.org/10.3390/rs70302509

Delsinne T., Sonet G., Nagy Z.T., Wauters N., Jacquemin J. \& Leponce M. 2012. High species turnover of the ant genus Solenopsis (Hymenoptera: Formicidae) along an altitudinal gradient in the Ecuadorian Andes, indicated by a combined DNA sequencing and morphological approach. Invertebrate Systematics 26: 457-469. http://dx.doi.org/10.1071/IS12030

Donoso D.A., Vieira J.M. \& Wild A.L. 2006. Three new species of Leptanilloides Mann from Andean Ecuador (Formicidade: Leptanilloidinae). Zootaxa 1201: 47-62.

Folmer O., Black M., Hoeh W., Lutz R. \& Vrijenhoek R. 1994. DNA primers for amplification of mitochondrial cytochrome $\mathrm{C}$ oxidase subunit I from diverse metazoan invertebrates. Molecular Marine Biology and Biotechnology 3: 294-299.

Goerner A., Gloaguen R. \& Makeschin F. 2007. Monitoring of the Ecuadorian mountain rainforest with remote sensing. Journal of Applied Remote Sensing 1: 1-12. http://dx.doi.org/10.1117/1.2784111

Hadley A. 2010. CombineZP. Available from http://www.hadleyweb.pwp.blueyonder.co.uk/ [accessed 6 Jun. 2010]

Homeier J., Werner F.A., Breckle S.-W., Gradstein S.R. \& Richter M. 2008. Potential vegetation and floristic composition of Andean forests in South Ecuador, with a focus on the Reserva San Francisco. In: Beck E., Bendix J., Kottke I., Makeschin F. \& Mosandl R. (eds) Gradients in a Tropical Mountain Ecosystem of Ecuador: 87-100. Ecological Studies 198, Springer, Berlin. http://dx.doi.org/10.1007/978$\underline{3-540-73526-7}$

Homeier J., Hertel D., Camenzind T., Cumbicus N.L., Maraun M., Martinson G.O., Poma N.L., Rillig M.C., Sandmann D., Scheu S., Veldkamp E., Wilcke W., Wullaert H. \& Leuschner C. 2012. Tropical Andean forests are highly susceptible to nutrient inputs-Rapid effects of experimental $\mathrm{N}$ and $\mathrm{P}$ addition to an Ecuadorian montane forest. PLoS ONE 7 (10): e47128. http://dx.doi.org/10.1371/journal. pone. 0047128

Jukes T.H. \& Cantor C.R. 1969. Evolution of protein molecules. In: Munro H.M. (ed.) Mammalian Protein Metabolism: 21-132. Academic Press, New York.

Kronauer D.J.C. \& Boomsma J.J. 2007. Do army ant queens re-mate later in life? Insectes Sociaux 54: 20-28. http://dx.doi.org/10.1007/s00040-007-0904-2

Lanfear R., Calcott B., Ho S.Y.W. \& Guindon S. 2012. PartitionFinder: Combined selection of partitioning schemes and substitution models for phylogenetic analyses. Molecular Biology and Evolution 29: 16951701. http://dx.doi.org/10.1093/molbev/mss020

Lesaffre E. \& Lawson A.B. 2012. Bayesian Biostatistics, First Edition. John Wiley \& Sons Ltd., Chichester, UK.

Longino J.T. 2003. A new Costa Rican species of Leptanilloides (Hymenoptera: Formicidae: doryline section: Leptanilloidinae). Zootaxa 264: 1-6.

Mann W.M. 1923. Two new ants from Bolivia. Psyche 30: 13-18. http://dx.doi.org/10.1155/1923/58289

Paradis E., Claude J. \& Strimmer K. 2004. APE: analyses of phylogenetics and evolution in R language. Bioinformatics 20: 289-290. http://dx.doi.org/10.1093/bioinformatics/btg412 
Posada D. 2003. Using Modeltest and PAUP* to select a model of nucleotide substitution. In: Baxevanis A.D., Davison D.B., Page R.D.M., Petsko G.A., Stein L.D. \& Stormo G.D. (eds) Current Protocols in Bioinformatics: 6.5.1-6.5.14. John Wiley \& Sons, Hoboken, New Jersey.

Rambaut A., Suchard M.A., Xie D. \& Drummond A.J. 2014. Tracer, ver. 1.6. Available from http:// beast.bio.ed.ac.uk/Tracer [accessed 17 Aug. 2015]

Ratnasingham S. \& Hebert P.D.N. 2007. The Barcode of Life Data System BOLD. Molecular Ecology Notes 7: 355-364. http://dx.doi.org/10.1111/j.1471-8286.2007.01678.x

Ronquist F., Huelsenbeck J. \& Teslenko M. 2011. Draft MrBayes version 3.2 manual: tutorials and model summaries. Available from http://mrbayes.sourceforge.net/manual.php [accessed 10 Mar. 2015]

Ronquist F., Teslenko M., van der Mark P., Ayres D.L., Darling A., Höhna S., Larget B., Liu L. \& Suchard M.A. 2012. MrBayes 3.2: efficient Bayesian phylogenetic inference and model choice across a large model space. Systematic Biology 61: 539-542. http://dx.doi.org/10.1093/sysbio/sys029

Ryder Wilkie K.T., Mertl A.L. \& Traniello J.F.A. 2007. Biodiversity below ground: probing the subterranean ant fauna of Amazonia. Naturwissenschaften 94: 725-731. http://dx.doi.org/10.1007/ $\underline{\mathrm{s} 00114-007-0250-2}$

SAS Institute. 2009. SAS/STAT® 9.2, User's Guide, Second Edition. SAS Institute Inc., Cary, North Carolina.

Schliep K.P. 2011. phangorn: phylogenetic analysis in R. Bioinformatics 27 (4): 592-593. http://dx.doi. org/10.1093/bioinformatics/btq706

Schmidt F.A. \& Solar R.R.C. 2010. Hypogaeic pitfall traps: methodological advances and remarks to improve the sampling of a hidden ant fauna. Insectes Sociaux 57: 261-266. http://dx.doi.org/10.1007/ s00040-010-0078-1

Shik J.Z., Donoso D.A. \& Kaspari M. 2013. The life history continuum hypothesis links traits of male ants with life outside the nest. Entomologia Experimentalis et Applicata 149: 99-109. http://dx.doi. org/10.1111/eea.12117

Silva R.R., Feitosa R.M., Brandão C.R.F. \& Freitas A.V.L. 2013. The first Leptanilloides species (Hymenoptera: Formicidae: Leptanilloidinae) from eastern South America. Journal of Natural History 47 (31-32): 2039-2047. http://dx.doi.org/10.1080/00222933.2012.763058

Silvestre R., Demétrio M.F. \& Delabie J.H.C. 2012. Community structure of leaf-litter ants in a Neotropical dry forest: a biogeographic approach to explain betadiversity. Psyche 2012: e306925. http:// dx.doi.org/10.1155/2012/306925

Tamura K., Stecher G., Peterson D., Filipski A. \& Kumar S. 2013. MEGA6: Molecular evolutionary genetics analysis, version 6.0. Molecular Biology and Evolution 30: 2725-2729. http://dx.doi. org $/ 10.1093 / \mathrm{molbev} / \mathrm{mst} 197$

Tejedor Garavito N., Álvarez E., Arango Caro S., Araujo Murakami A., Blundo C., Boza Espinoza T.E., La Torre Cuadros M.A., Gaviria J., Gutiérrez N., Jørgensen P.M., León B., López Camacho R., Malizia L., Millán B., Moraes M., Pacheco S., Rey Benayas J.M., Reynel C., Timaná de la Flor M., Ulloa Ulloa C., Vacas Cruz O. \& Newton A.C. 2012. Evaluación del estado de conservación de los bosques montanos en los Andes Tropicales. Ecosistemas 21 (1-2): 148-166.

Thies B., Meyer H., Nauss T. \& Bendix J. 2014. Projecting land-use and land-cover changes in a tropical mountain forest of Southern Ecuador. Journal of Land Use Science 9: 1-33. http://dx.doi.org/10.1080/ $\underline{1747423 X .2012 .718378}$ 
Thompson J.D., Higgins D.G. \& Gibson T.J. 1994. CLUSTAL W: improving the sensitivity of progressive multiple sequence alignment through sequence weighting, position-specific gap penalties and weight matrix choice. Nucleic Acids Research 22: 4673-4680. http://dx.doi.org/10.1093/nar/22.22.4673

Ward P.S. 2007. The ant genus Leptanilloides: discovery of the male and evaluation of phylogenetic relationships based on DNA sequence data. In: Snelling R.R., Fisher R.B. \& Ward P.S. (eds) Advances in Ant Systematics (Hymenoptera: Formicidae): Homage to E.O. Wilson - 50 Years of Contributions: 637-649. Memoirs of the American Entomological Institute 80, American Entomological Institute, Gainesville, FL.

Ward P.S. \& Downie D.A. 2005. The ant subfamily Pseudomyrmecinae (Hymenoptera: Formicidae): Phylogeny and evolution of big-eyed arboreal ants. Systematic Entomology 30: 310-335. http://dx.doi. org/10.1111/j.1365-3113.2004.00281.x

Ward P.S \& Brady S.G. 2009. Rediscovery of the ant genus Amyrmex Kusnezov (Hymenoptera: Formicidae) and its transfer from Dolichoderinae to Leptanilloidinae. Zootaxa 2063: 46-54.

Weissflog A., Sternheim E., Dorow W.H.O., Berghoff S. \& Maschwitz U. 2000. How to study subterranean army ants: a novel method for locating and monitoring field populations of the South East Asian army ant Dorylus (Dichthadia) laevigatus Smith, 1857 (Formicidae, Dorylinae) with observations on their ecology. Insectes Sociaux 47: 317-324. http://dx.doi.org/10.1007/PL00001723

Zabala G.E., Vélez M.H. \& Góngora C.B. 2006. Nuevos registros de especies de hormigas (Hymenoptera: Formicidae) para Colombia. Revista Colombiana de Entomología 32 (2): 227-229.

Zwickl D.J. 2006. Genetic Algorithm Approaches for the Phylogenetic Analysis of Large Biological Sequence Datasets under the Maximum Likelihood Criterion. PhD Thesis. University of Texas at Austin, Texas.

Manuscript received: 22 June 2015

Manuscript accepted: 12 August 2015

Published on: 8 October 2015

Topic editor: Koen Martens

Desk editor: Danny Eibye-Jacobsen

Printed versions of all papers are also deposited in the libraries of the institutes that are members of the EJT consortium: Muséum National d'Histoire Naturelle, Paris, France; Botanic Garden Meise, Belgium; Royal Museum for Central Africa, Tervuren, Belgium; Natural History Museum, London, United Kingdom; Royal Belgian Institute of Natural Sciences, Brussels, Belgium; Natural History Museum of Denmark, Copenhagen, Denmark. 
DELSINNE T., SONET G. \& DONOSO D.A., Two new Leptanilloides from Ecuador

\section{Appendix 1}

Nexus file with all aligned sequences of the wingless gene (Wg) used in this paper and Mr Bayes command block.

\#NEXUS

begin data; dimensions $n t a x=10$ nchar $=412$;

format missing $=$ ? gap $=$ - datatype $=$ dna;

matrix

4052311_L_prometea

ACTACCGAACTTCCGCGTTGTCGGCGACAACCTGAAGGATCGTTTCGACGGCGCGTCCCGGGTGATGGTGACCAATTCGGACCGCGCCCGCATCATCGCAGCTAACGCGATTACCAGCAACTCGGCCAGCAACTCCGTGCACCAGCACCGCGGCGGTCTCGCACGCCGGCAGCGCTACAATTTCCAATTAAAACCGTACAATCCGGAGCACAAGCCGCCCGGGCGCAAGGACCTCGTCTACGTGGAAACGTCGCCGGGCTTCTGCGAGAAGAACCCGAAATTCGGCATCCTCGGCACGCAGGGCCGTCAGTGCAACGACACCAGCATCGGCGTCGACGGGTGCGACTTGATGTGCTGCGGCAGAGGCTACAAGACCCAGGAGGTGACGGTGA?CGAGAGGT?C??CTGCTCC

FJ588490_Amyrmex_BR01

GCTGCCGAACTTCCGCGTTGTCGGCGACAACCTGAAGGACCGTTTCGACGGCGCGTCGCGGGTAATGGTGACCAACTCGGACCGCGCCCGCATCATCGCGGCTAACGCGATTACCAGCAACTCGGCCAGCAACTCCGTGCACCAGCACCGCGGCGGTCTCGCACGCCGGCAGCGCTACAATTTCCAACTGAAACCGTACAATCCGGAGCACAAGCCGCCCGGGCGCAAGGACCTCGTCTACGTGGAGGCGTCGCCGGGCTTCTGCGAGAAGAACCCGAAATTCGGCATCCTCGGCACCCACGGCCGCCAGTGCAACGATACCAGCATCGGCGTCGACGGATGCGACCTGATGTGCTGCGGCAGGGGCTACAAGACCCAGGAGGTAACAGTGATCGAGAGGTGCGCCTGCACC

KJ523541_L_nubecula GCTGCCGAACTTCCGCTCTGTCGGCGACAACCTGAAGGACCGTTTCGACGGCGCGTCCCGGGTGATGATGACCCTCTCGGACCGCCCCCGCAGC---GCGGCGAACGCGATTATCAGCAACTCGGCCAGCAACTCCGTGCACCAGCACCGGAGCGGTCTCGCGCGCCGCCAGCGCTACAACTTCCAGCTGAAACCGTACAATCCGGAGCACAAGCCGCCCGGGCGCAAGGACCTCGTTTACGTGGAAGCGTCGCCGGGTTTCTGCGAGAGGAACCCGAAATTCGGCATCATGGGCACCCACGGCCGCCAGTGCAACGACACCAGCATCGGCGTCGACGGCTGCGACCTCATGTGCTGCGGCAGGGGCTACAAGACCCAGGAGGTGACGGTGATCGAGAGGTGCGCCTGCACG

KJ523540_L_gracilis GCTGCCCAACTTCCGCGTCGTCGGCGACAACCTGAAGGACCGTTTCGACGGCGCGTCCCGGGTAATGGTGACCAATTCCGACCGCGCCCGCATCATCGCGGCTAACGCGATTACCAGCAACTCGGCCAGCAATTCCGTGCACCAGCACCGCGGCGGCCTCGTGCGCCGGCAGCGCTACCATTTCCAGCTGAAACCGTACAATCCGGAGCACAAGCCGCCCGGGCGCAAGGACCTCGTCTACGTGGAGGCGTCGCCGGGCTTCTGCGAGAAGAACCCGCGATTCGGCATCCTCGGCACCCACGGACGCCAGTGCAACGACACCAGCATCGGCGTCGACGGCTGCGACCTCATGTGCTGCGGCAGGGGCTACAAGACCCAGGAGGTCACGGTGATCGAGAGGTGCGCCTGCACC

KJ523539_L_femoralis GCTACCGAACTTCCGCGTTGTCGGCGACAACTTGAAGGACCGTTTCGACGGGGCGTCCCGGGTGATGGTGACCAACTCGGACCGCGCCCGCATCATCGCGGCTAACGCGATTACCAGCAACTCGGCCAGCAACTCCGTGCACCAGCACCGCGGCGGTCTTGCACGCCGGCAGCGC- 
TACAATTTCCAACTGAAACCGTACAACCCGGAGCACAAGCCGCCAGGGCGCAAGGACCTCGTGTACGTGGAGACGTCGCCGGGCTTCTGCGAGAAGAACCCGAAATTCGGCATTATGGGCACCCACGGCCGGCAATGCAACGACACCAGCATTGGCGTCGACGGGTGCGACCTCATGTGCTGCGGCAGGGGTTACAAGACCCAGGAGGTGACGGTGATCGAGAGGTGCGCCTGCACC

DQ353106_L_nomada GCTGCCCAACTTCCGCTCAGTCGGCGACAACCTGAAGGACCGTTTCGACGGCGCCTCGCGGGTGATGATTACCCTCTCGGACCGTCCCCGCAGC---GCGGCGAACGCGATTATCAGCAACTCGGCCAGCAACTCCGTGCACCAGCACCGGAGCGGTCTCGCGCGCCGCCAGCGCTACAACTTCCAGCTGAAACCGTACAATCCGGAGCACAAGCCGCCCGGGCGCAAGGACCTCGTGTACGTGGAAGCGTCGCCGGGTTTCTGCGAGAGGAACCCGAAATTCGGCATCATGGGCACCCACGGCCGGCAGTGCAACGACACCAGCATCGGCGTCGACGGCTGCGACCTGATGTGCTGCGGCAGGGGCTACAAGACCCAGGAGGTGACGGTGATCGAGAGGTGCGCCTGCACG

AY867429_L_mckennae GCTGCCGAACTTCCGCTCTGTCGGCGACAACCTGAAGGACCGTTTCGACGGCGCGTCCCGGGTGATGATGACCCTGTCGGACCGCCCCCGCAGC---GCGGCGAACGCGATTATCAGCAACTCGGCCAGCAACTCCGTGCACCAGCACCGTAGCGGTCTCGCGCGCCGCCAGCGCTACAACTTCCAGCTGAAGCCGTACAATCCGGAGCACAAGCCGCCCGGGCGCAAGGACCTCGTGTACGTGGAGGCGTCGCCGGGTTTCTGCGAGAAGAACCCGAAATTCGGCATCATGGGCACCCACGGCCGGCAGTGCAACGACACCAGCATCGGCGTCGACGGCTGCGACCTAATGTGCTGCGGCAGGGGCTACAAGACCCAGGAGGTGACGGTGATCGAGAGGTGCGCCTGCACG

KJ523535_C_meinerti GCTGCC $\bar{C}$ AACTTCCGCGTGGTCGGCGACAACCTGAAGGACCGCTTCGACGGCGCGTCACGAGTGATGGTGACCAACTCGGATCGCGCCCGCAGC---AACGCCAACGCCATCATCAGCAACTCGGCCAGCAACTCCGTGCACAATCACCGCGGTGGTCTGGGACGTCGGCAGCGCTACAACATCCAGCTGAAGCCGTACAATCCGGAGCACAAGCCGCCCGGGAGCAAGGACCTCGTGTACGTGGAGCCGTCGCCGCCGTTCTGCGAGAAGAACCCGAAACTCGGGATCCTGGGCACCCACGGCCGGCAGTGCAACGACACGAGCATCGGCGTCGATGGCTGCGACCTGATGTGCTGCGGCAGAGGCTACAAGACCGAGGAGGTGACGGTGATCGAGAGGTGCGCCTGCACG

AY233640_C_striatus ACTGCCGAACTTCCGCGTGGTCGGCGACAACCTGAAGGACCGCTTCGACGGCGCGTCTCGAGTGATGGTGACGAACTCGGATCGCGCTCGCGGC---AACGCGAACGCCATCATCAGCAACTCGGCCAGCAACTCCGTGCACCATCACCGCGCTGGGCTGGGACGTCGGCAGCGCTACAACATCCAGCTGAAGCCGTACAATCCGGAGCACAAGCCGCCCGGCAGCAAGGACCTCGTCTACGTGGAGCCGTCGCCGCCGTTCTGCGAGAAGAACCCGAAACTCGGCATCCTGGGCACCCACGGCCGGCAGTGCAACGACACCAGCATCGGCGTCGACGGCTGCGACCTGATGTGCTGCGGCAGGGGCTACAAGACCGAGGAGGTGACGGTGATCGAGAGGTGCGCC??????

AY867426_C_striatus ACTGCCGAACTTCCGCGTGGTCGGCGACAATCTGAAGGACCGCTTCGACGGCGCGTCTCGAGTGATGGTGACGAACTCGGATCGCGCTCGCGGC---AACGCGAACGCCATCATCAGCAACTCGGCCAGCAACTCCGTGCACCATCACCGCGCTGGGCTGGGACGTCGGCAGCGCTACAACATCCAGCTGAAGCCGTACAATCCGGAGCACAAGCCGCCCGGCAGCAAGGACCTCGTCTACGTGGAGCCGTCGCCGCCGTTCTGCGAGAAGAACCCGAAACTCGGCATCCTGGGCACCCACGGCCGGCAGTGCAACGACACCAGCATCGGCGTCGACGGCTGCGACCTGATGTGCTGCGGCAGGGGCTACAAGACCGAGGAGGTGACGGTGATCGAGAGGTGCGCCTGCACG 
;

end;

begin sets;

charset $1 \mathrm{st}=2-412 \backslash 3$;

charset $2 \mathrm{nd}=3-412 \backslash 3$;

charset $3 r d=1-412 \backslash 3$;

charpartition bypart $={ }_{w g} 1: 1 \mathrm{st}, \mathrm{wg} 2: 2 \mathrm{nd}, \mathrm{wg} 3: 3 \mathrm{rd}$;

end;

begin codons;

codonposset $*$ coding $=$

$1: 2-412 \backslash 3$,

2:3-412\3,

$3: 1-412 \backslash 3$;

end;

\section{BEGIN MRBAYES;}

outgroup 10;

charset $\mathrm{wg} 1=2-412 \backslash 3$;

charset $\mathrm{wg} 2=3-412 \backslash 3$;

charset $\mathrm{wg} 3=1-412 \backslash 3$;

partition genes $=3: \mathrm{wg} 1, \mathrm{wg} 2, \mathrm{wg} 3$;

set partition $=$ genes;

lset applyto $=(2,3) \mathrm{nst}=1$;

lset applyto=(1) nst=6;

lset applyto $=(1)$ rates $=$ Gamma;

lset applyto $=(2,3)$ rates $=$ Equal;

unlink statefreq $=($ all $)$ revmat $=($ all $)$ shape $=($ all $)$ pinvar $=($ all $)$;

prset applyto $=($ all $)$ ratepr $=$ variable;

mcmcp ngen $=10000000$ printfreq $=1000$ samplefreq $=1000$ nchains $=4$ savebrlens $=$ yes filename $=\mathrm{w}-$ ghok_BI;

memc;

end; 


\section{Appendix 2}

R script used for the parsimony analysis.

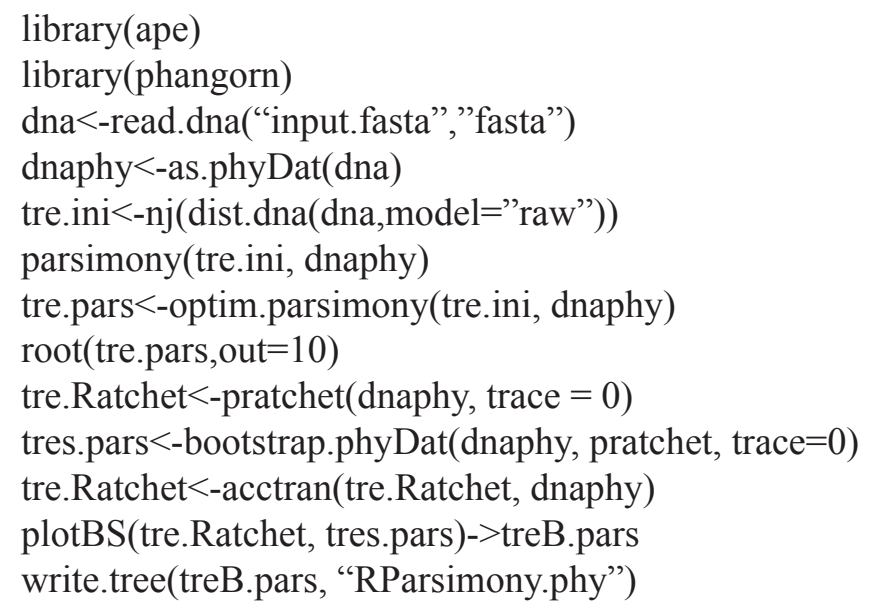




\section{Appendix 3}

Configuration file used for the maximum likelihood analysis using GARLI ver. 2.0 (Zwick1 2006)..

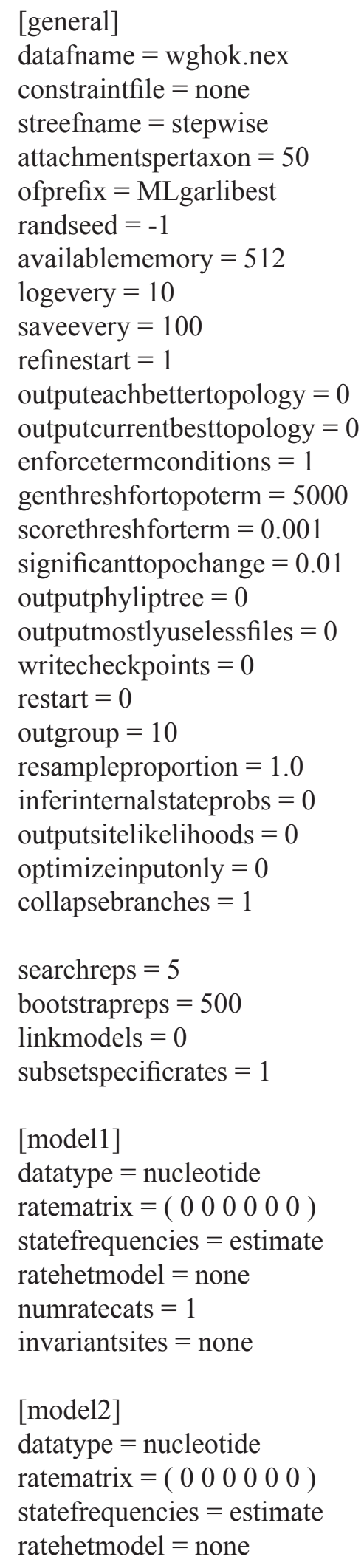

